\title{
Fifteen years monitoring of extragalactic radio sources at 22, 37 and $87 \mathrm{GHz}$
}

\author{
H. Teräsranta ${ }^{1}$, M. Tornikoski ${ }^{1}$, A. Mujunen ${ }^{1}$, K. Karlamaa ${ }^{1}$, T. Valtonen ${ }^{1}$, N. Henelius ${ }^{1}$, S. Urpo ${ }^{1}$, M. Lainela $^{2}$, \\ T. Pursimo ${ }^{2}$, K. Nilsson ${ }^{2}$, S. Wiren ${ }^{2}$, A. Lähteenmäki ${ }^{2}$, M. Korpi ${ }^{2}$, R. Rekola ${ }^{2}$, P. Heinämäki ${ }^{2}$, M. Hanski ${ }^{2}$, \\ P. Nurmi ${ }^{2}$, K. Kokkonen ${ }^{2}$, P. Keinänen ${ }^{2}$, O. Joutsamo ${ }^{2}$, J. Oksanen ${ }^{2}$, H. Pietilä ${ }^{2}$, E. Valtaoja ${ }^{2}$, M. Valtonen ${ }^{2}$, and \\ P. Könönen ${ }^{3}$ \\ 1 Metsähovi Radio Research Station, Helsinki University of Technology, FIN-02540 Kylmälä, Finland \\ 2 Tuorla Observatory, FIN-21500 Piikkiö, Finland \\ 3 Observatory, PO Box 14, University of Helsinki, FIN-00014 Helsinki, Finland
}

Received February 20; accepted April 7, 1998

\begin{abstract}
Over 13600 continuum observations of extragalactic sources are presented ${ }^{1}$. These observations of 157 sources at 22,37 and $87 \mathrm{GHz}$ more than doubles the millimeter observations of these sources. The data are between 1990.5 and 1995.5 , and combined with our earlier published data they form a 15 year database.
\end{abstract}

Key words: galaxies: active - BL Lacertae objects: general — quasars: general — radio continuum: galaxies — radio continuum: general

\section{Introduction}

Observing extragalactic radio sources, generally speaking quasars has, been increasingly popular during the last years due to the numerous space borne instruments dedicating a large share of their observing time to this field. Instruments like EGRET onboard the Compton GRO (gamma rays), IUE (ultraviolet), GINGA, ASCA, XTE and ROSAT (X-rays), ISO (infrared) and many others have prompted coordinated groundbased observations. Two observing windows can be covered from the ground: the radio window (below $300 \mathrm{GHz}$ ) and the optical window. Monitoring of extragalactic radio sources has been continued with the

Send offprint requests to: $\mathrm{H}$. Teräsranta

Correspondence to: hte@alpha.hut.fi

1 The data (Table 3) are only available in electronic form at the CDS via anonymous ftp to cdsarc.ustrasbg.fr (130.79.128.5) or via http://cdsweb.ustrasbg.fr/Abstract.html
Metsähovi radio telescope since 1980, most of the observations being at 22 and $37 \mathrm{GHz}$. Our sample mostly consists of Northern flat spectrum sources which have at least once reached $2 \mathrm{Jy}$ at $22 \mathrm{GHz}$ (Valtaoja et al. 1992). At lower frequencies $(5,8$ and $14 \mathrm{GHz})$ the Michigan group has been monitoring a larger sample, which also includes most of our sources, since 1965 (Aller et al. 1985). At still higher radio frequencies there are three monitoring efforts: our 90, 135 and $230 \mathrm{GHz}$ monitoring of southern sources with the SEST-telescope (Tornikoski et al. 1996), the Ian Robson team working with the JCMT-telescope at 150 , 230, 270 and $375 \mathrm{GHz}$ (Stevens et al. 1994), as well as the IRAM-team at 90, 142 and $230 \mathrm{GHz}$ (Reuter et al. 1997) and in references therein. At optical wavelengths there are several monitoring efforts concentrating on AGN, like the ones at Tuorla Observatory (Sillanpää et al. 1991), at Rosemary Hill Observatory (Webb et al. 1988), at Foggy Bottom Observatory, at Calar Alto Observatory by the Hamburg Quasar Monitoring Program (Schramm et al. 1994) and the Heidelberg group, at Asiago Observatory (Barbieri et al. 1977), at Perugia University Observatory (Fiorucci \& Tosti 1996), at Torino Observatory (Villata et al. 1997), at Dodaira Station (Kikuchi 1988) and at the Yunnan Observatory (Xie et al. 1994). The Western Kentucky University has a new automated AGN monitoring program with two optical telescopes (Hackney et al. 1996). Typically the variations in AGN are slower at radio frequencies than at higher frequency bands and thus the sampling density does not have to be so high. A monthly sampling will usually be adequate for cm-observations. Below $3 \mathrm{~mm}$ you should have weekly observations to get most of the variations covered. At optical frequencies even faster sampling would be desired. 
Table 1. Receiver parameters

\begin{tabular}{lllll}
\hline $\begin{array}{l}\text { Frequency } \\
\text { GHz }\end{array}$ & $H P B W$ & $\begin{array}{l}\text { Beam } \\
\text { separation }\end{array}$ & \multicolumn{2}{l}{$B(\mathrm{IF})$} \\
$\mathrm{MHz}$ & $T_{\text {sys }}$ & $\mathrm{K}$ DSB \\
\hline 22.2 & $4.0^{\prime}$ & $12.0^{\prime}$ & 1000 & $850^{\mathrm{a}}$ \\
22.2 & $4.0^{\prime}$ & $10.1^{\prime}$ & 500 & $300^{\mathrm{b}}$ \\
36.8 & $2.4^{\prime}$ & $6.0^{\prime}$ & 1000 & 500 \\
87.3 & $1.1^{\prime}$ & $3.2^{\prime}$ & 500 & 200 \\
\hline
\end{tabular}

a Before June 1993.

${ }^{b}$ After June 1993.

Table 2. Parameters $K_{4}$ and $K_{5}$ with the old and new antenna

\begin{tabular}{lllll}
\hline Frequency & $K_{4}($ old $)$ & $K_{4}($ new $)$ & $K_{5}($ old $)$ & $K_{5}($ new $)$ \\
\hline $22 \mathrm{GHz}$ & 4.0 & 3.0 & 0.15 & 0.22 \\
$37 \mathrm{GHz}$ & 9.1 & 6.5 & 0.15 & 0.22 \\
$87 \mathrm{GHz}$ & 46.0 & 17.0 & 0.15 & 0.22 \\
\hline
\end{tabular}

\section{Observations}

The observations presented here were done with the Metsähovi Radio Telescope during 1990.5-1995.5 at 22, 37 and $87 \mathrm{GHz}$. The Metsähovi $13.7 \mathrm{~m}$ diameter ESSCO design antenna is placed inside a radome. In August 1991 the original radome was replaced with a new one. Also the reflector panels and the back structure of the antenna were replaced with more accurate ones during the summer of 1994. The receiving system parameters are listed in Table 1. The flux density scale is calibrated against DR 21 , our primary calibration source. Its fluxes at 22,37 and $87 \mathrm{GHz}$ are 19.0, 17.9 and 17.0 Jy, respectively, according to Baars et al. (1977) and Ulich (1981). As secondary calibration sources we have used 3C 274 and planets like Jupiter. The receivers at 22 and $37 \mathrm{GHz}$ are of a dual beam type with a ferrite swich operating at $25 \mathrm{~Hz}$. At $87 \mathrm{GHz}$ the beam switching at a rate of $20 \mathrm{~Hz}$ is performed with a rotating chopper-wheel. The old $22 \mathrm{GHz}$ mixer front end receiver was replaced with a more sensitive one with a low noise HEMT amplifier as a first stage in June 1993. The $37 \mathrm{GHz}$ receiver is a mixer front end receiver operating at room temperature. The $87 \mathrm{GHz}$ receiver is a Schottky mixer front end receiver cooled to $20 \mathrm{~K}$.

\section{Data reduction}

The data reduction is similar to the one described in Teräsranta et al. (1992), although the upgrading of the antenna lead to changes in some parameters. The fluxcalculating procedure is done with Eqs. (1) to (5). The error estimate for the flux is from Eq. (6), where the relative errors of the optical depth, noise tube calibration and flux integreation have been quadratically added.

$S=K_{1} K_{2} K_{3} \frac{U}{U_{\text {cal }}} \mathrm{e}^{\frac{\tau}{\sin (e l)}}$

$$
\begin{aligned}
& K_{2}=\frac{1}{\left(1-K_{4}\left(P-P_{\mathrm{opt}}\right)^{2}\right)} \\
& P_{\mathrm{opt}}=P_{0}-K_{5} \sin (e l)-K_{6} T \\
& K_{3}=1+(\theta / H P B W)^{2}, \text { for Gaussian sources } \\
& K_{3}=(\theta / 0.6 / H P B W)^{2} /\left(1-\mathrm{e}^{\left.-(\theta / 0.6 / H P B W)^{2}\right)},\right. \\
& \text { for planets } \\
& \delta S=S \sqrt{\left.(\delta U / U)^{2}+(\delta \tau / \sin (e l))^{2}+(\delta C a l / U c a l)^{2}\right)}
\end{aligned}
$$

In the formulae,

$S \quad$ the flux density in Jy

$U$ the observed voltage from the A/D converter

$U_{\text {cal }}$ the exess voltage coming from the noise tube calibration

$K_{1} \quad$ the factor for converting receiver voltages to Janskys

$\tau \quad$ the optical depth of the atmosphere

el the elevation angle during the observation

$K_{2} \quad$ the correction for the antenna focusing

$K_{3}$ the correction factor for source size

$K_{4}$ the frequency dependent focus sharpness factor

$K_{5} \quad$ the elevation dependent factor of the focus

$K_{6} \quad$ the temperature dependent factor of the focus

$P$ the position of the subreflector during the observation(milli-inch)

$P_{\text {opt }} \quad$ the optimal position of the subreflector during the observation(milli-inch)

$P_{0} \quad$ the position of the receiver focus in respect to the antenna focus (milli-inch)

$T$ the physical temperature of the antenna $\left(0^{\circ} \mathrm{C}\right)$

$\theta \quad$ the source diameter

$H P B W$ the antenna half power beam width

$\delta S \quad$ the error estimate for the observation

$\delta U$ the rms error of the integration

$\delta \tau \quad$ the error of the estimation of the optical depth

$\delta \mathrm{Cal}$ the error of the noise tube calibration.

The optimal position of the antenna focus is a function of the elevation angle and temperature according to Eq. (3). Two fixed positions for the focus were used, one for the summer and one for the winter. This kept the correction factor $K_{2}$ still quite small at the used elevation range from 20 to 70 degrees. As the corrections for the focus-offset are larger at higher frequencies, the results at $87 \mathrm{GHz}$ are more severely affected. In Table 2 . the values of the parameters $K_{4}$ and $K_{5}$ are tabulated at each observing frequency with the old (before summer 1994) and new antenna (after summer 1994). The parameter $K_{6}$ was the same 0.0025 with both antennas.

\section{Results}

The list of sources with classification and number of observations at each frequency is shown in Table 3 . In the 
source classification HPQ states that the source has been recorded at least once an optical polarization level equal or above $3.0 \%$, for the LPQ type sources the polarization level has allways been below $3.0 \%$. BL Lac type object are identified with BLO and galaxies with GAL. Sources with no classification have no optical polarization observation from the literature or have simply no optical counterpart like NRAO 150. Due to the large number of data points (over 13000), the numerical tables are available only in electronic form at the CDS via anonymous ftp. The data in Table 4 consists of date (year, month, day and hour(ut)) and the flux (Jy) and 1 sigma error estimate (Jy). There are 157 sources in Table 4, from which about 85 belong to our main sample. Some additional sources have also been observed during many multifrequency campaigns, but that data will be published elsewhere. The flux curves for the 44 best observed sources are given in Fig. 1. The numerical values for some sources during 1988 and 1989 in Fig. 1 are found in Wiren et al. (1992). The flux curves in the figures contain the whole 15 year span of our observations. The numerical values for the observations prior 1990.5 can be found in Salonen et al. (1987), Teräsranta et al. (1987) and Teräsranta et al. (1992). The flux densities in Fig. 1 are weekly mean values to allow an easier examination of the flux development. For many sources there are long periods of daily observations, which can be found in Table 4.

Generally the sources seem to vary on these frequencies on a monthly basis, the shorter variations are usually within the error bars. In some cases, like in $0202+149$, there was one considerably higher flux point. When combined with another observation within a week for the figure it produced a giant error bar. Another example is in OL 093 where we also had an anomalous high value. These have been carefully checked and as no fault was found they remain in the database. At our highest observing frequency $(87 \mathrm{GHz})$, the poor antenna surface accuracy prior to summer 1994 limited the observations to only a few sessions.
Acknowledgements. This work has been supported by the Academy of Finland.

\section{References}

Aller H.D., Aller M.F., Latimer G.E., Hodge P.E., 1985, ApJS 59,513

Baars J.W.M., Gentzel R., Pauline-Toth I.I.K., Witzel A., 1977, A\&A 61, 99

Barbieri C., Romano G., Di Serego A., et al., 1977, A\&A 59, 419

Fiorucci M., Tosti G., 1996, A\&AS 117, 475

Hackney R., Hackney K., Scott R., et al., 1996, at Blazar Continuum Variability conference, PASPC 110, p. 166

Kikuchi S., 1988, Tokyo Astron. Bull., No. 281, p. 3267

Reuter H.-P., Kramer C., Sievers A., et al., 1997, A\&AS 122, 271

Salonen E., Teräsranta H., Urpo S., et al., 1987, A\&AS 70, 409

Schramm K.J., Borgeest U., Kühl D., et al., 1994, A\&AS 106, 349

Sillanpää A., Mikkola S., Valtaoja L., 1991, A\&AS 88, 225

Stevens J.A., Litchfield S.J., Robson E.I., et al., 1994, ApJ 437, 91

Teräsranta H., Valtaoja E., Haarala S., et al., 1987, A\&AS 71, 125

Teräsranta H., Tornikoski M., Valtaoja E., et al., 1992, A\&AS 94, 121

Tornikoski M., Valtaoja E., Teräsranta H., et al., 1996, A\&AS 116,157

Ulich B., 1981, AJ 86, 1619

Valtaoja E., Lähteenmäki A., Teräsranta H., 1992, A\&AS 95, 73

Villata M., Raiteri C.M., Chisellinei G., et al., 1997, A\&AS 121,119

Wiren S., Valtaoja E., Teräsranta H., Kotilainen J., 1992, AJ 104, 1009

Webb J.R., Smith A.G., Leacock R.J., et al., 1988, AJ 95, 374

Xie G.Z., Li K.H., Zhang Y.H., et al., 1994, A\&AS 106, 361 
Table 3. Source list with classification and number of observations at each frequency

\begin{tabular}{|c|c|c|c|c|c|}
\hline Designatic & ther nam & lassificati & n2 & & 87 \\
\hline $0003-066$ & & $\mathrm{BLO}$ & 15 & 16 & 0 \\
\hline $0007+106$ & III ZW 2 & LPQ & 62 & 83 & 0 \\
\hline $0016+731$ & & LPQ & 40 & 45 & 0 \\
\hline $0048-097$ & & BLO & 16 & 18 & 0 \\
\hline $0106+013$ & OC 012 & HPQ & 49 & 61 & 0 \\
\hline $0109+224$ & & $\mathrm{BLO}$ & 58 & 69 & 2 \\
\hline $0122-003$ & & LPQ & 3 & 2 & 0 \\
\hline $0135+476$ & DA 55 & HPQ & 66 & 71 & 4 \\
\hline $0149+218$ & & & 47 & 50 & 0 \\
\hline $0153+744$ & & LPQ & 9 & 3 & 0 \\
\hline $0202+149$ & & HPQ & 69 & 79 & 2 \\
\hline $0212+735$ & & $\mathrm{BLO}$ & 24 & 17 & 0 \\
\hline $0215+015$ & & BLO & 1 & 2 & 0 \\
\hline $0218+357$ & & & 20 & 11 & 0 \\
\hline $0219+428$ & $3 \mathrm{C} 66 \mathrm{~A}$ & BLO & 21 & 15 & 3 \\
\hline $0221+067$ & & & 1 & 4 & 0 \\
\hline $0224+671$ & & & 37 & 43 & 0 \\
\hline $0229+131$ & & LPQ & 3 & 7 & 0 \\
\hline $0229+341$ & & HPQ & 2 & 1 & 0 \\
\hline $0234+285$ & & $\mathrm{HPQ}$ & 52 & 53 & 1 \\
\hline $0235+164$ & & $\mathrm{BLO}$ & 91 & 105 & 8 \\
\hline $0238-084$ & & GAL & 11 & 15 & 0 \\
\hline $0248+430$ & & LPQ & 39 & 50 & 0 \\
\hline $0300+470$ & & $\mathrm{BLO}$ & 8 & 7 & 0 \\
\hline $0306+102$ & & BLO & 8 & 8 & 0 \\
\hline $0316+413$ & $3 \mathrm{C} 84$ & GAL & 190 & 223 & 12 \\
\hline $0323+022$ & & BLO & 6 & 2 & 0 \\
\hline $0333+321$ & NRAO 140 & LPQ & 61 & 62 & 1 \\
\hline 0336-019 & CTA 26 & $\mathrm{BLO}$ & 23 & 26 & 0 \\
\hline $0355+508$ & NRAO 150 & & 62 & 79 & 1 \\
\hline $0415+379$ & $3 \mathrm{C} 111$ & & 15 & 15 & 0 \\
\hline $0420-014$ & OA 129 & HPQ & 100 & 108 & 5 \\
\hline $0422+004$ & & $\mathrm{BLO}$ & 45 & 50 & 0 \\
\hline $0430+052$ & $3 \mathrm{C} 120$ & GAL & 88 & 86 & 1 \\
\hline $0440-003$ & NRAO 190 & HPQ & 9 & 5 & 2 \\
\hline $0446+112$ & & GAL & 18 & 11 & 2 \\
\hline $0454+844$ & & $\mathrm{BLO}$ & 4 & 0 & 0 \\
\hline $0454+039$ & & LPQ & 29 & 33 & 0 \\
\hline $0458-020$ & & HPQ & 44 & 47 & 1 \\
\hline $0528+134$ & & LPQ & 116 & 122 & 12 \\
\hline $0552+398$ & DA 193 & LPQ & 72 & 80 & 5 \\
\hline $0605-085$ & & HPQ & 12 & 15 & 0 \\
\hline $0642+449$ & $\mathrm{OH} 471$ & LPQ & 61 & 66 & 3 \\
\hline $0707+476$ & & LPQ & 3 & 0 & 0 \\
\hline $0716+714$ & & $\mathrm{BLO}$ & 47 & 49 & 0 \\
\hline $0723-008$ & & & 7 & 5 & 0 \\
\hline $0723+679$ & & LPQ & 6 & 2 & 0 \\
\hline $0735+178$ & & $\mathrm{BLO}$ & 74 & 89 & 6 \\
\hline $0736+017$ & & HPQ & 54 & 61 & 5 \\
\hline $0738+313$ & & LPQ & 4 & 1 & 0 \\
\hline $0741-063$ & & & 0 & 1 & 0 \\
\hline $0742+103$ & & & 11 & 6 & 0 \\
\hline $0743-006$ & & BLO & 7 & 4 & 0 \\
\hline $0748+126$ & & LPQ & 2 & 0 & 0 \\
\hline $0754+100$ & OI 090.4 & BLO & 55 & 59 & 1 \\
\hline $0804+499$ & & HPQ & 93 & 103 & 5 \\
\hline
\end{tabular}

Table 3. continued

\begin{tabular}{|c|c|c|c|c|c|}
\hline Designatior & tther nar & class & $\mathrm{n} 2 \mathrm{Z}$ & & 87 \\
\hline $0814+425$ & & BLO & 57 & 68 & 3 \\
\hline $0820+225$ & & BLO & 9 & 10 & 0 \\
\hline $0823+033$ & & HPQ & 3 & 6 & 0 \\
\hline $0827+243$ & & LPQ & 13 & 7 & 1 \\
\hline $0828+493$ & & BLO & 9 & 6 & 0 \\
\hline $0829+046$ & & BLO & 1 & 1 & 0 \\
\hline $0836+710$ & & LPQ & 33 & 25 & 0 \\
\hline $0846+513$ & & $\mathrm{BLO}$ & 41 & 40 & 0 \\
\hline $0850+581$ & & LPQ & 4 & 2 & 0 \\
\hline $0851+202$ & OJ 287 & BLO & 205 & 214 & 15 \\
\hline $0859+470$ & & LPQ & 6 & 7 & 0 \\
\hline $0906+430$ & $3 \mathrm{C} 216$ & HPQ & 12 & 5 & 0 \\
\hline $0912+297$ & & HPQ & 2 & 1 & 0 \\
\hline $0923+392$ & $4 \mathrm{C} 39.25$ & LPQ & 156 & 172 & 10 \\
\hline $0927+352$ & & & 5 & 3 & 1 \\
\hline $0945+408$ & & LPQ & 7 & 6 & 0 \\
\hline $0953+254$ & & LPQ & 51 & 55 & 1 \\
\hline $0954+556$ & & HPQ & 26 & 23 & 2 \\
\hline $0954+658$ & & BLO & 41 & 48 & 0 \\
\hline $0957+227$ & & BLO & 5 & 4 & 0 \\
\hline $1038+528$ & & HPQ & 5 & 3 & 0 \\
\hline $1039+811$ & & & 4 & 2 & 0 \\
\hline $1040+123$ & & LPQ & 8 & 6 & 0 \\
\hline $1049+215$ & & LPQ & 8 & 5 & 0 \\
\hline $1055+018$ & OL 093 & HPQ & 53 & 81 & 0 \\
\hline $1057+100$ & & BLO & 3 & 4 & 0 \\
\hline $1101+384$ & Mark 421 & BLO & 49 & 46 & 6 \\
\hline $1133+704$ & & $\mathrm{BLO}$ & 3 & 0 & 0 \\
\hline $1137+660$ & & LPQ & 1 & 0 & 0 \\
\hline $1146-037$ & & LPQ & 22 & 29 & 0 \\
\hline $1147+245$ & & BLO & 11 & 9 & 0 \\
\hline $1150+497$ & & HPQ & 6 & 2 & 0 \\
\hline $1156+295$ & 4C 29.45 & $\mathrm{HPQ}$ & 85 & 109 & 7 \\
\hline $1215+303$ & & $\mathrm{BLO}$ & 8 & 5 & 0 \\
\hline $1218+304$ & & BLO & 2 & 2 & 0 \\
\hline $1219+285$ & ON 231 & BLO & 75 & 77 & 1 \\
\hline $1222+216$ & & & 30 & 23 & 1 \\
\hline $1226+023$ & $3 \mathrm{C} 273$ & LPQ & 244 & 265 & 12 \\
\hline $1229-021$ & & LPQ & 2 & 0 & 0 \\
\hline $1253-055$ & $3 \mathrm{C} 279$ & HPQ & 199 & 220 & 11 \\
\hline $1302-102$ & & LPQ & 3 & 3 & 0 \\
\hline $1308+326$ & & $\mathrm{BLO}$ & 87 & 84 & 7 \\
\hline $1308+328$ & & & 12 & 7 & 2 \\
\hline $1406-076$ & & & 14 & 12 & 3 \\
\hline $1413+135$ & & BLO & 88 & 88 & 4 \\
\hline $1418+546$ & OQ 530 & BLO & 65 & 69 & 2 \\
\hline $1502+106$ & OR 103 & HPQ & 51 & 53 & 3 \\
\hline $1510-089$ & & HPQ & 58 & 100 & 5 \\
\hline $1522+155$ & & HPQ & 3 & 2 & 0 \\
\hline $1538+149$ & 4C 14.60 & BLO & 66 & 67 & 1 \\
\hline $1546+027$ & & HPQ & 0 & 1 & 0 \\
\hline $1548+056$ & & HPQ & 5 & 4 & 0 \\
\hline $1553+113$ & & BLO & 4 & 3 & 0 \\
\hline $1606+106$ & & LPQ & 16 & 18 & 1 \\
\hline $1611+343$ & & LPQ & 84 & 111 & 4 \\
\hline $1633+382$ & 4C 38.41 & LPQ & 107 & 142 & 4 \\
\hline $1637+574$ & OS 562 & LPQ & 66 & 82 & 0 \\
\hline
\end{tabular}


Table 3. continued

\begin{tabular}{|c|c|c|c|c|c|}
\hline Designation & other name & classification & $\mathrm{n} 22$ & n37 & $\mathrm{n} 87$ \\
\hline $1641+399$ & $3 \mathrm{C} 345$ & HPQ & 200 & 270 & 7 \\
\hline $1642+690$ & & HPQ & 7 & 4 & 0 \\
\hline $1652+398$ & Mark 501 & $\mathrm{BLO}$ & 57 & 65 & 1 \\
\hline $1656+053$ & & HPQ & 0 & 2 & 0 \\
\hline $1725+044$ & & & 37 & 38 & 0 \\
\hline $1730-130$ & NRAO 530 & & 6 & 2 & 0 \\
\hline $1739+522$ & & HPQ & 60 & 68 & 0 \\
\hline $1741-038$ & & HPQ & 60 & 84 & 4 \\
\hline $1749+096$ & OT 081 & $\mathrm{BLO}$ & 129 & 152 & 6 \\
\hline $1749+701$ & & $\mathrm{BLO}$ & 13 & 12 & 0 \\
\hline $1803+784$ & & $\mathrm{BLO}$ & 53 & 61 & 0 \\
\hline $1807+698$ & 3C 371 & $\mathrm{BLO}$ & 53 & 71 & 0 \\
\hline $1823+568$ & & $\mathrm{BLO}$ & 9 & 5 & 0 \\
\hline $1828+487$ & $3 \mathrm{C} 380$ & LPQ & 20 & 16 & 0 \\
\hline $1845+797$ & 3C 390.3 & GAL & 44 & 49 & 0 \\
\hline $1901+319$ & & & 12 & 8 & 1 \\
\hline $1928+738$ & & LPQ & 65 & 59 & 0 \\
\hline $1951+498$ & & & 5 & 3 & 0 \\
\hline $1954+513$ & & LPQ & 7 & 5 & 0 \\
\hline $2005+403$ & & & 83 & 108 & 1 \\
\hline $2007+776$ & & $\mathrm{BLO}$ & 46 & 58 & 0 \\
\hline $2021+614$ & OW 637 & LPQ & 59 & 55 & 0 \\
\hline $2022+171$ & & & 7 & 2 & 2 \\
\hline $2030+407$ & CYG X-3 & & 20 & 85 & 0 \\
\hline $2037+511$ & & & 12 & 7 & 0 \\
\hline $2121+053$ & & HPQ & 8 & 7 & 0 \\
\hline $2131-021$ & & $\mathrm{BLO}$ & 16 & 16 & 0 \\
\hline $2134+004$ & OX 057 & LPQ & 58 & 82 & 0 \\
\hline $2136+141$ & OX 161 & LPQ & 12 & 10 & 0 \\
\hline $2141+175$ & OX 169 & LPQ & 11 & 14 & 0 \\
\hline $2144+092$ & OX 074 & & 9 & 10 & 0 \\
\hline $2145+067$ & & LPQ & 125 & 155 & 2 \\
\hline $2200+420$ & BL Lac & $\mathrm{BLO}$ & 175 & 240 & 11 \\
\hline $2201+315$ & & LPQ & 71 & 103 & 3 \\
\hline $2216-038$ & & LPQ & 18 & 19 & 0 \\
\hline $2223-052$ & $3 \mathrm{C} 446$ & HPQ & 62 & 82 & 0 \\
\hline $2225-055$ & & HPQ & 3 & 1 & 0 \\
\hline $2227-088$ & & HPQ & 14 & 18 & 0 \\
\hline $2230+114$ & CTA 102 & HPQ & 89 & 99 & 4 \\
\hline $2234+282$ & & HPQ & 11 & 7 & 0 \\
\hline $2251+158$ & $3 \mathrm{C} 454.3$ & HPQ & 196 & 241 & 10 \\
\hline $2254+074$ & & $\mathrm{BLO}$ & 29 & 38 & 0 \\
\hline $2319+272$ & & & 4 & 2 & 0 \\
\hline $2344+092$ & & LPQ & 10 & 9 & 0 \\
\hline
\end{tabular}



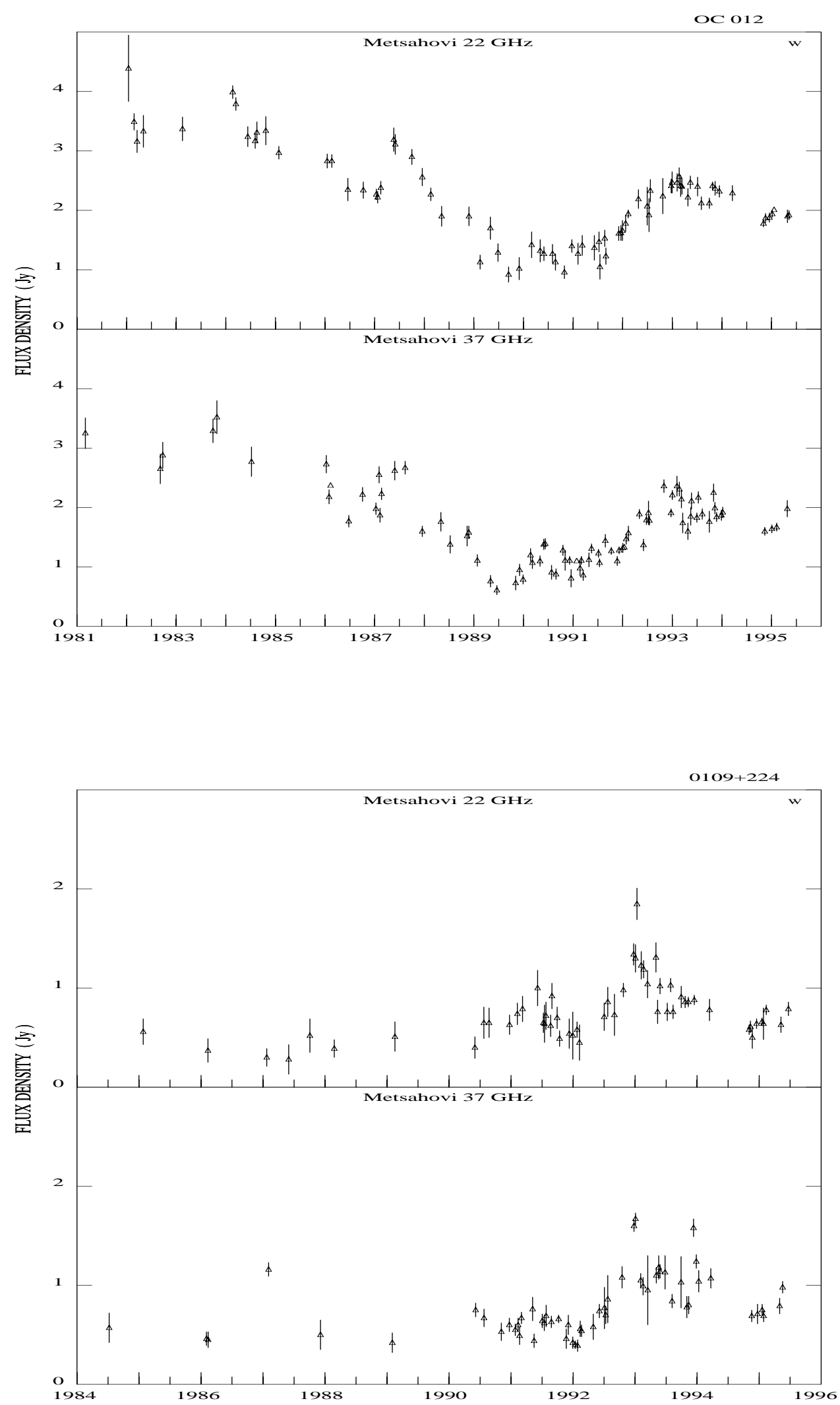

Fig. 1. Weekly mean flux density of observed sources at 22 and $37 \mathrm{GHz}$ 

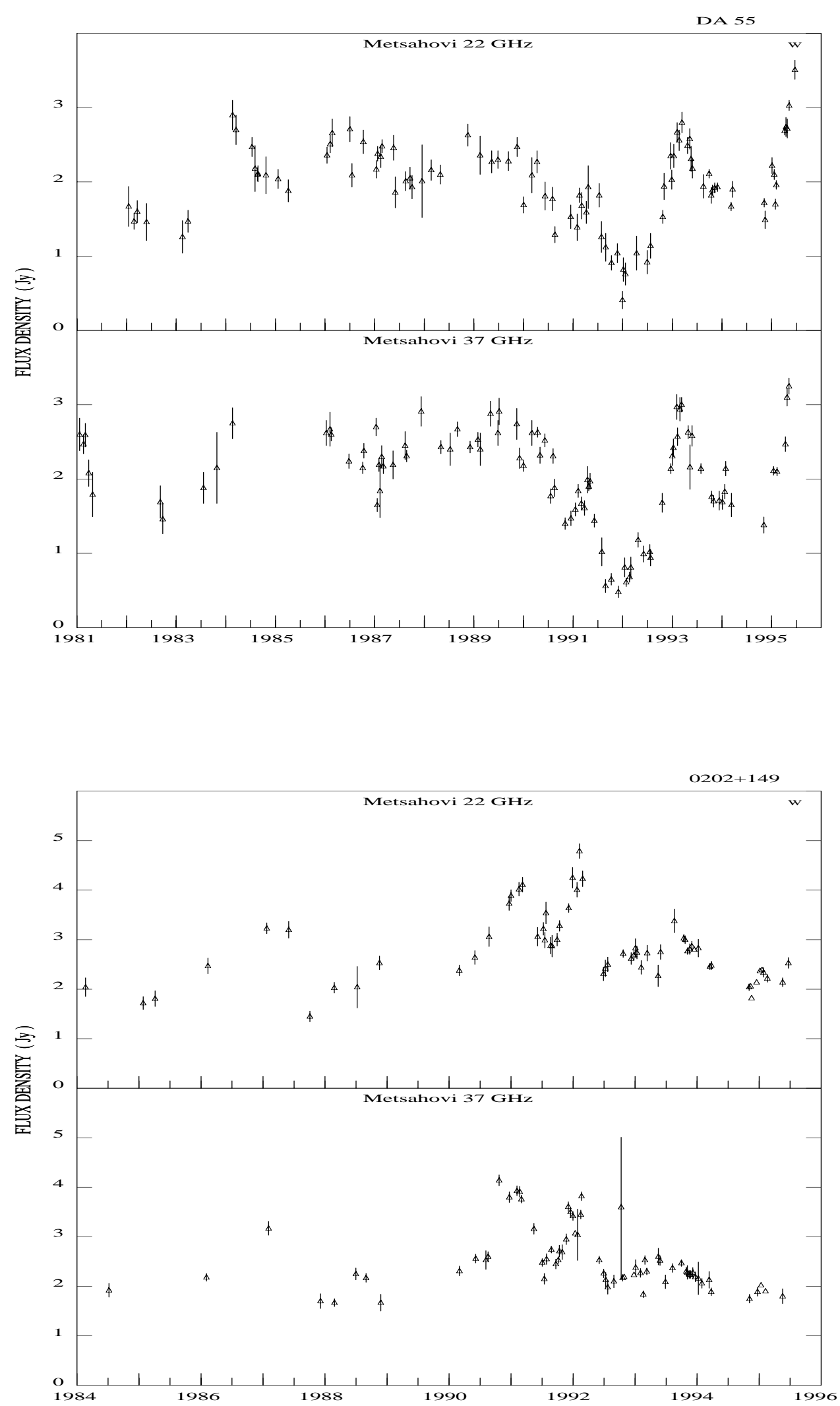

Fig. 1. continued 

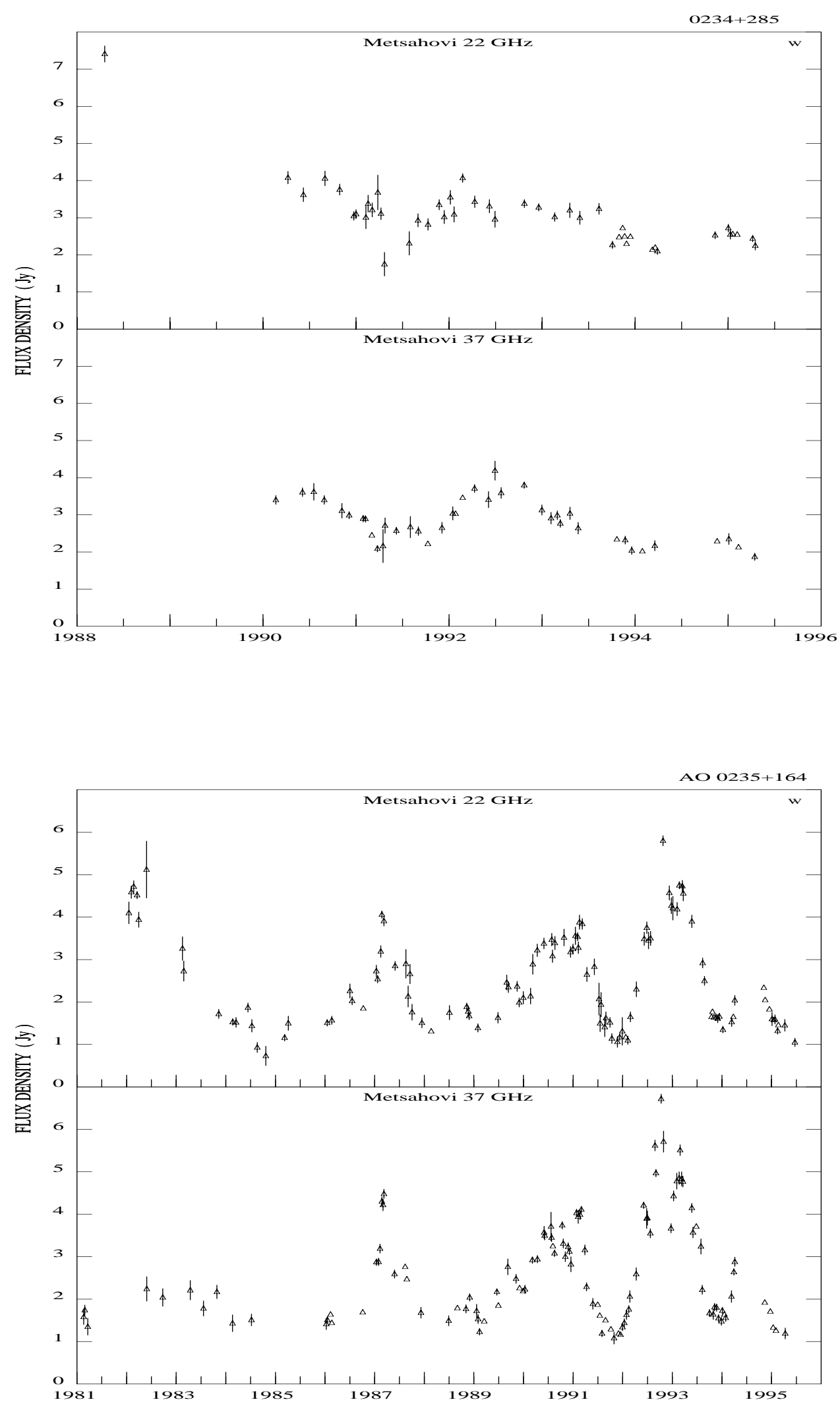

Fig. 1. continued 

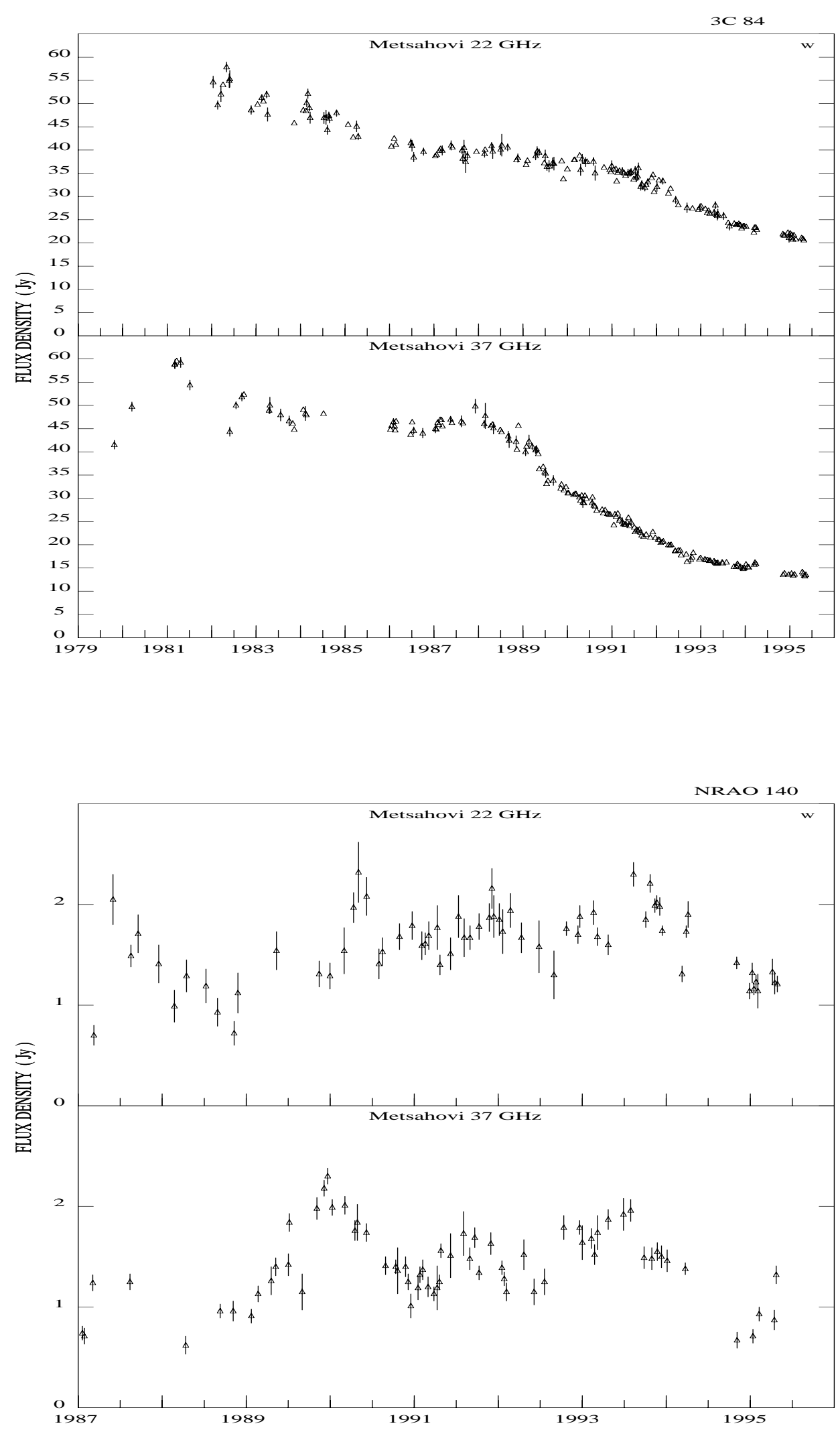

Fig. 1. continued 

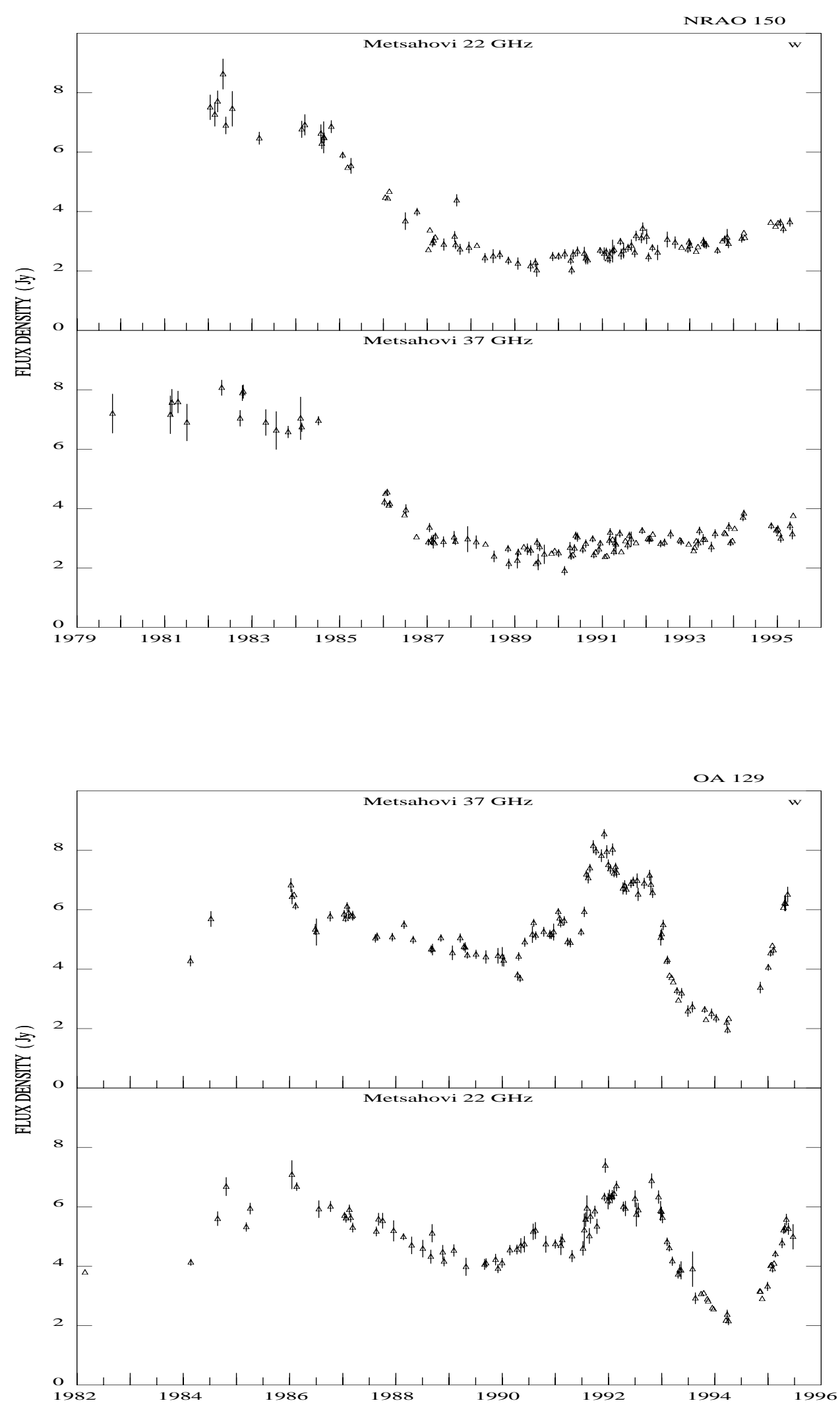

Fig. 1. continued 

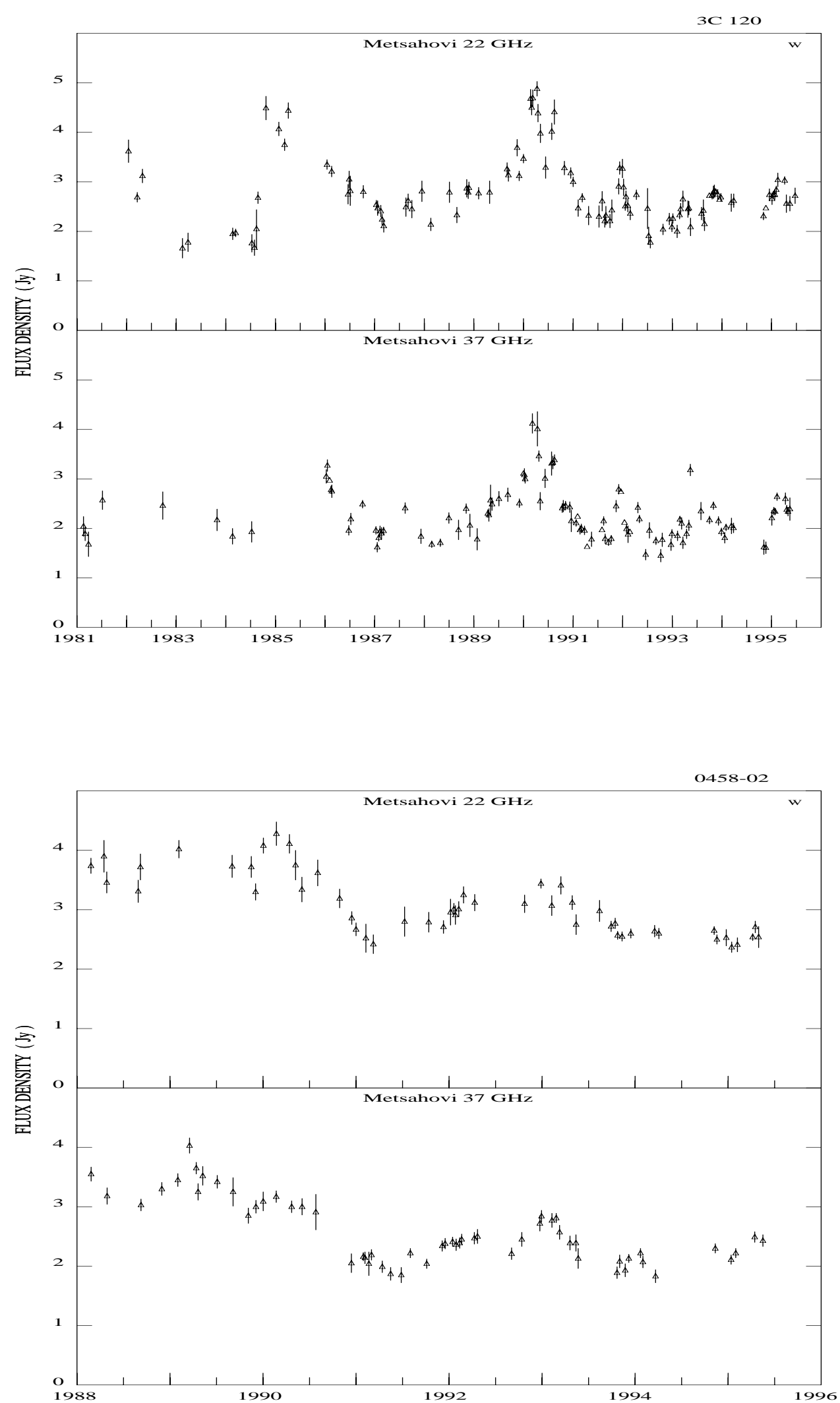

Fig. 1. continued 

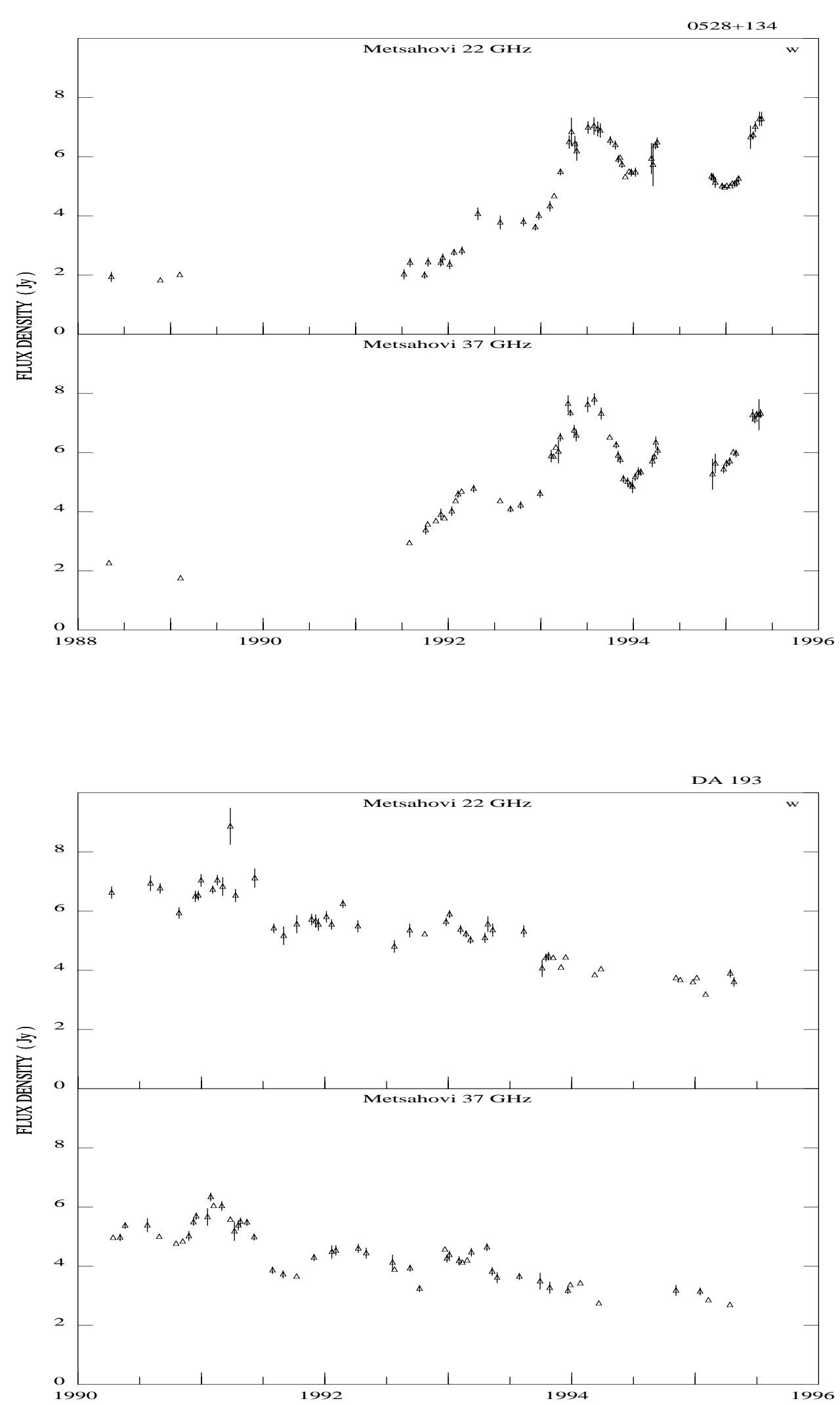

Fig. 1. continued 

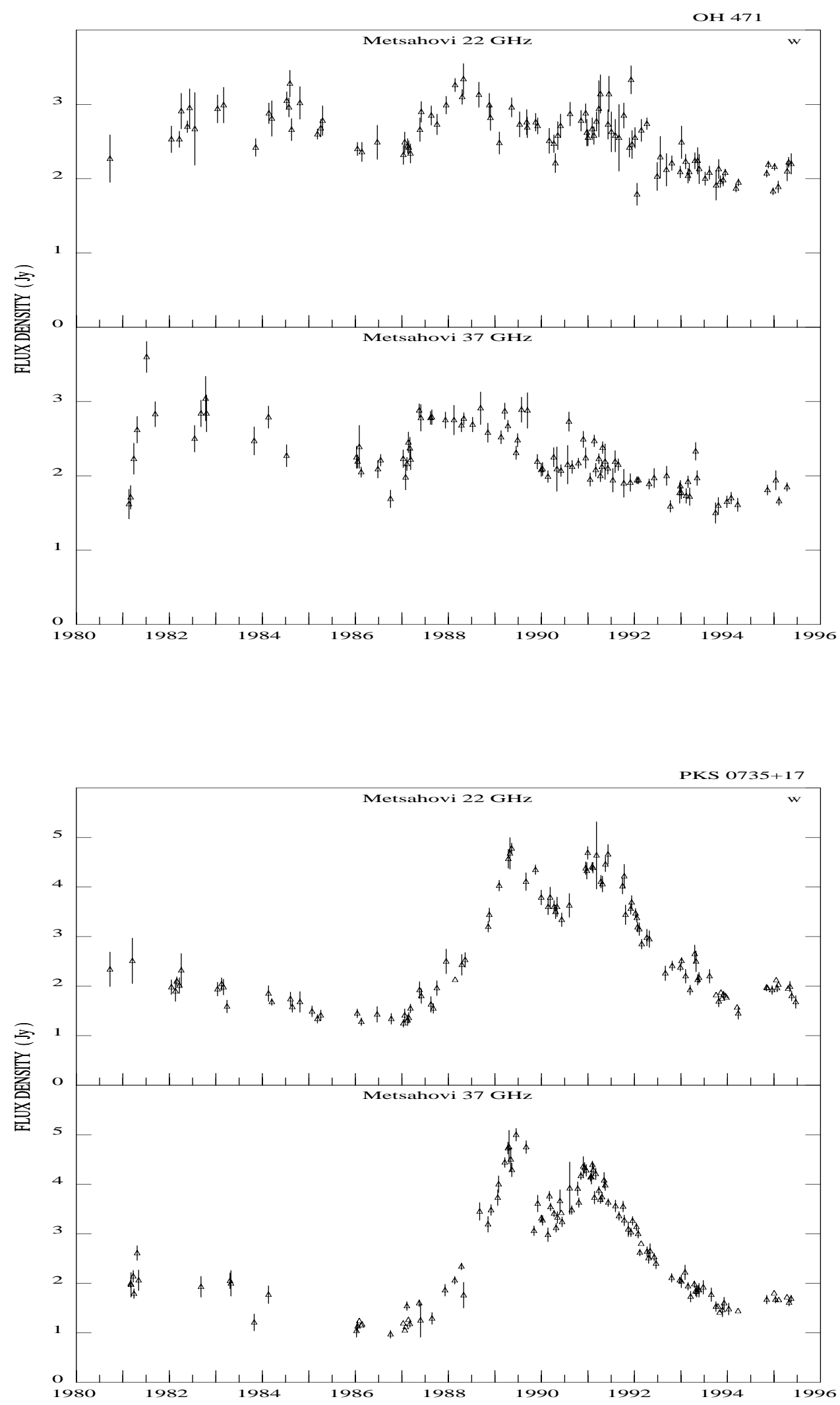

Fig. 1. continued 

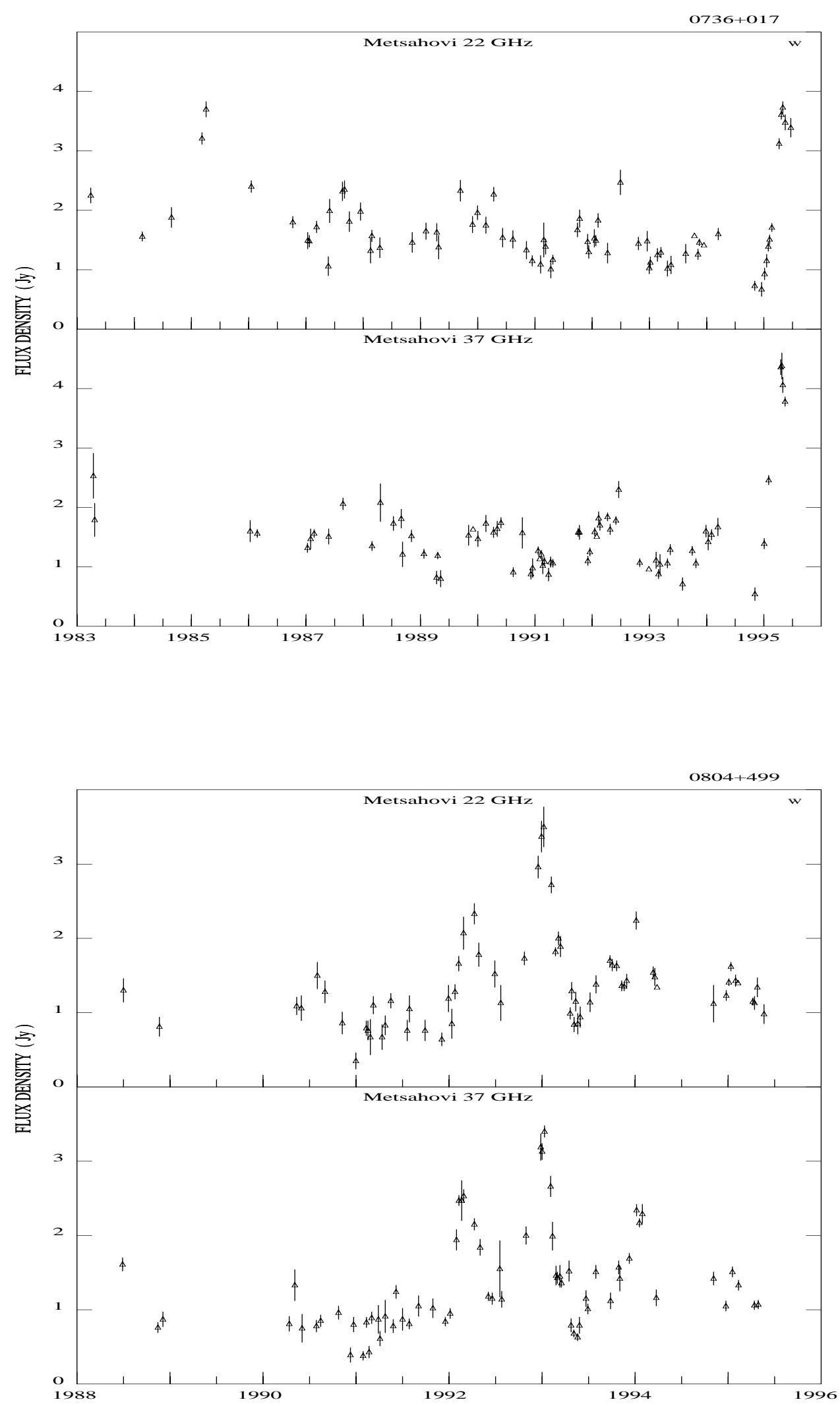

Fig. 1. continued 

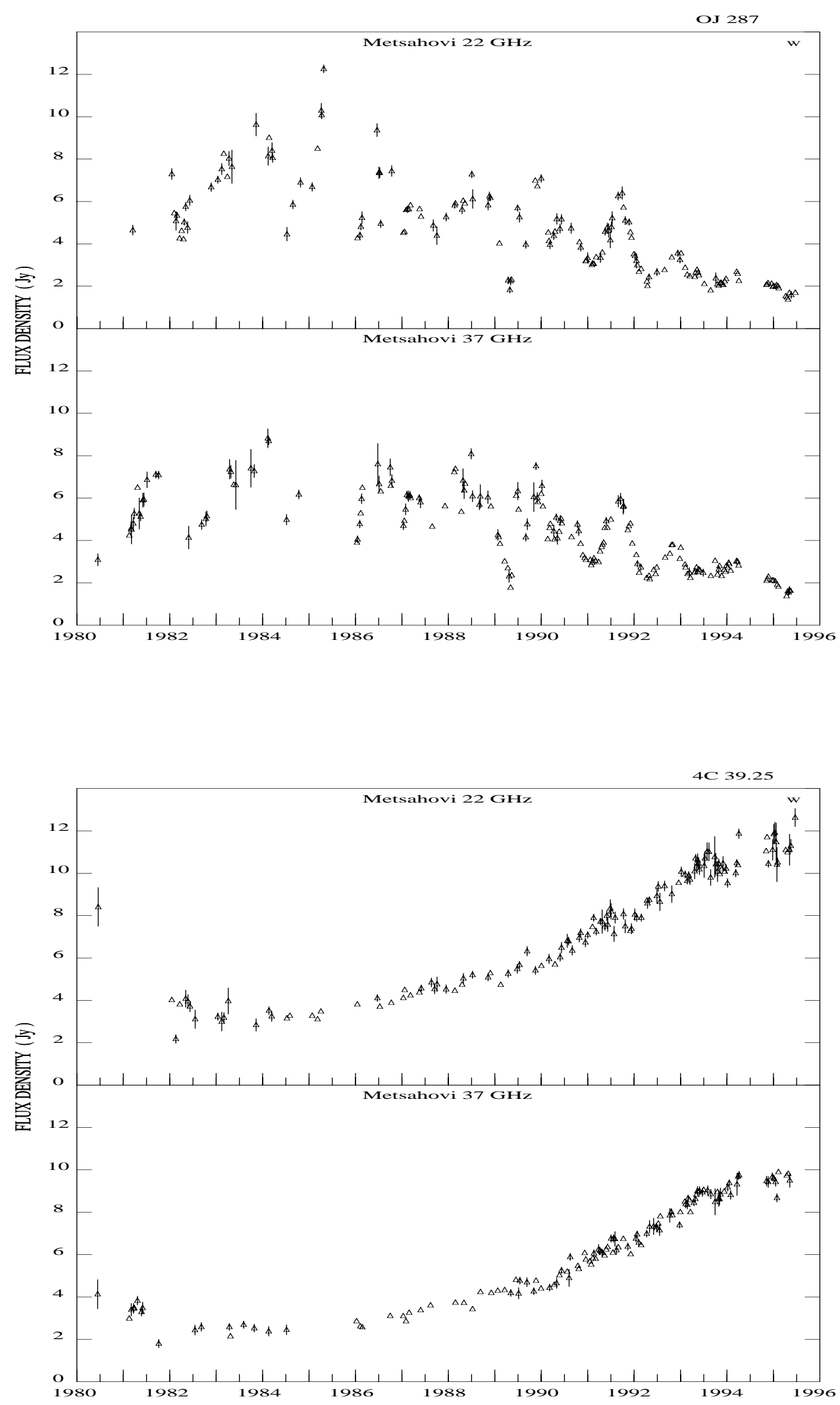

Fig. 1. continued 

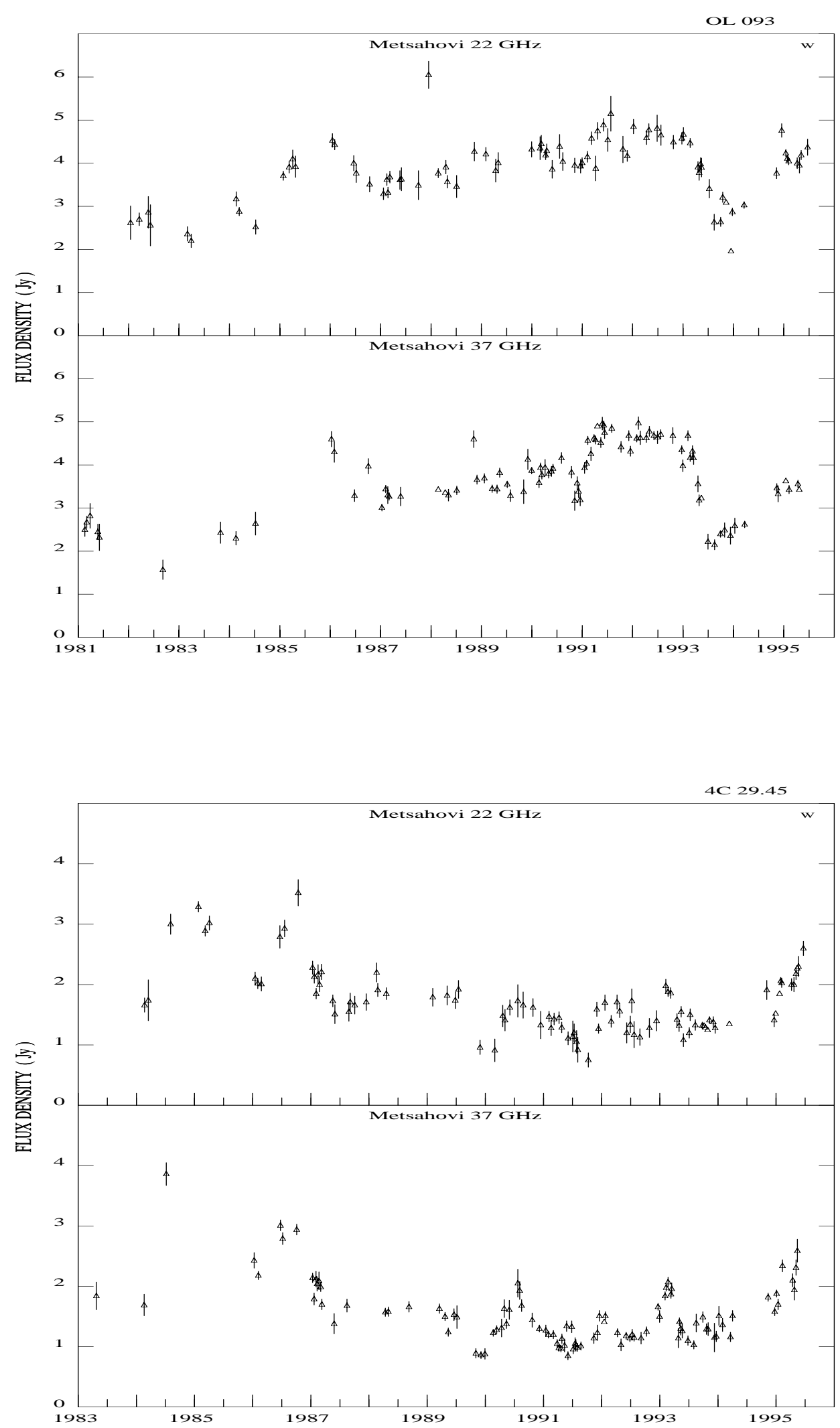

Fig. 1. continued 

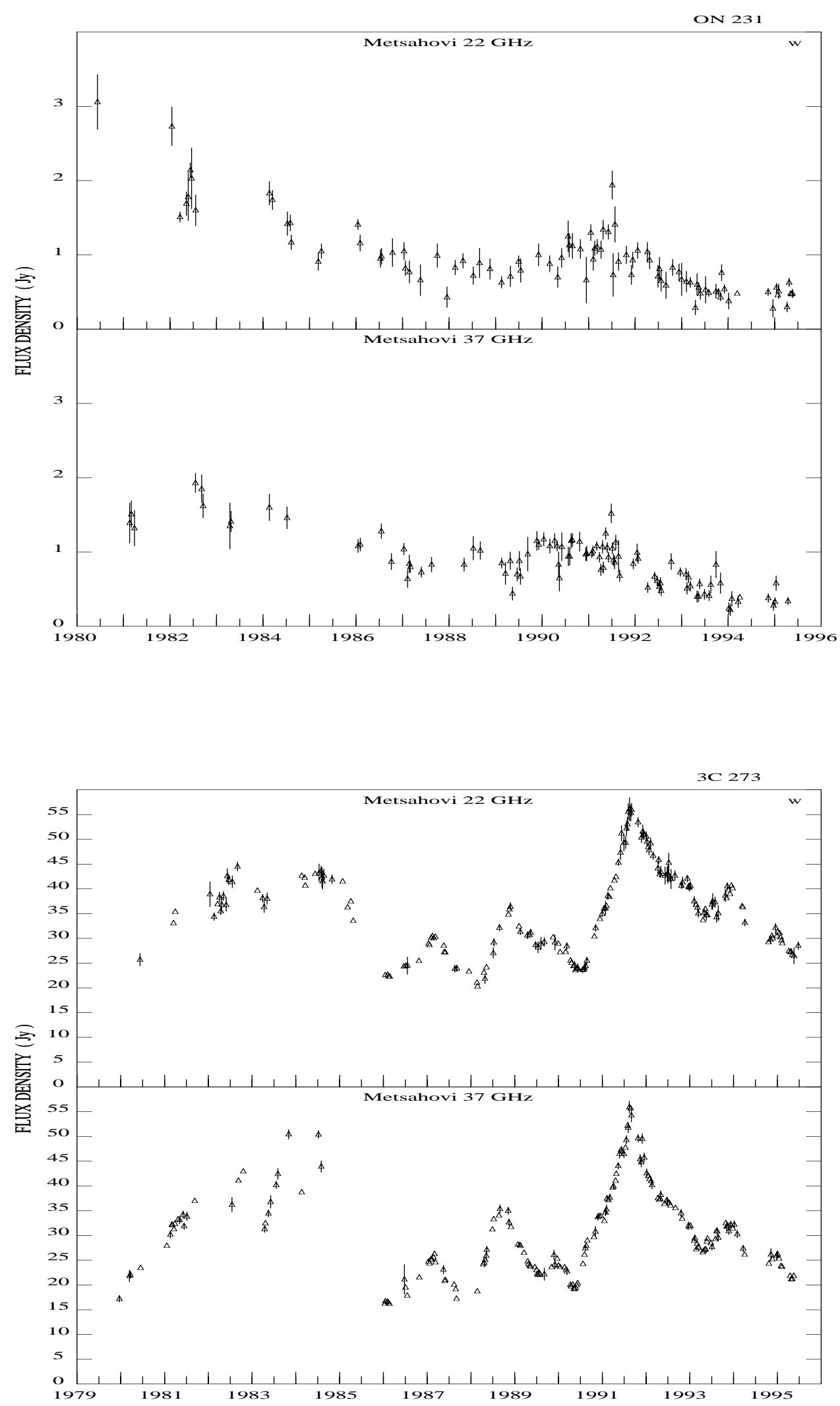

Fig. 1. continued 

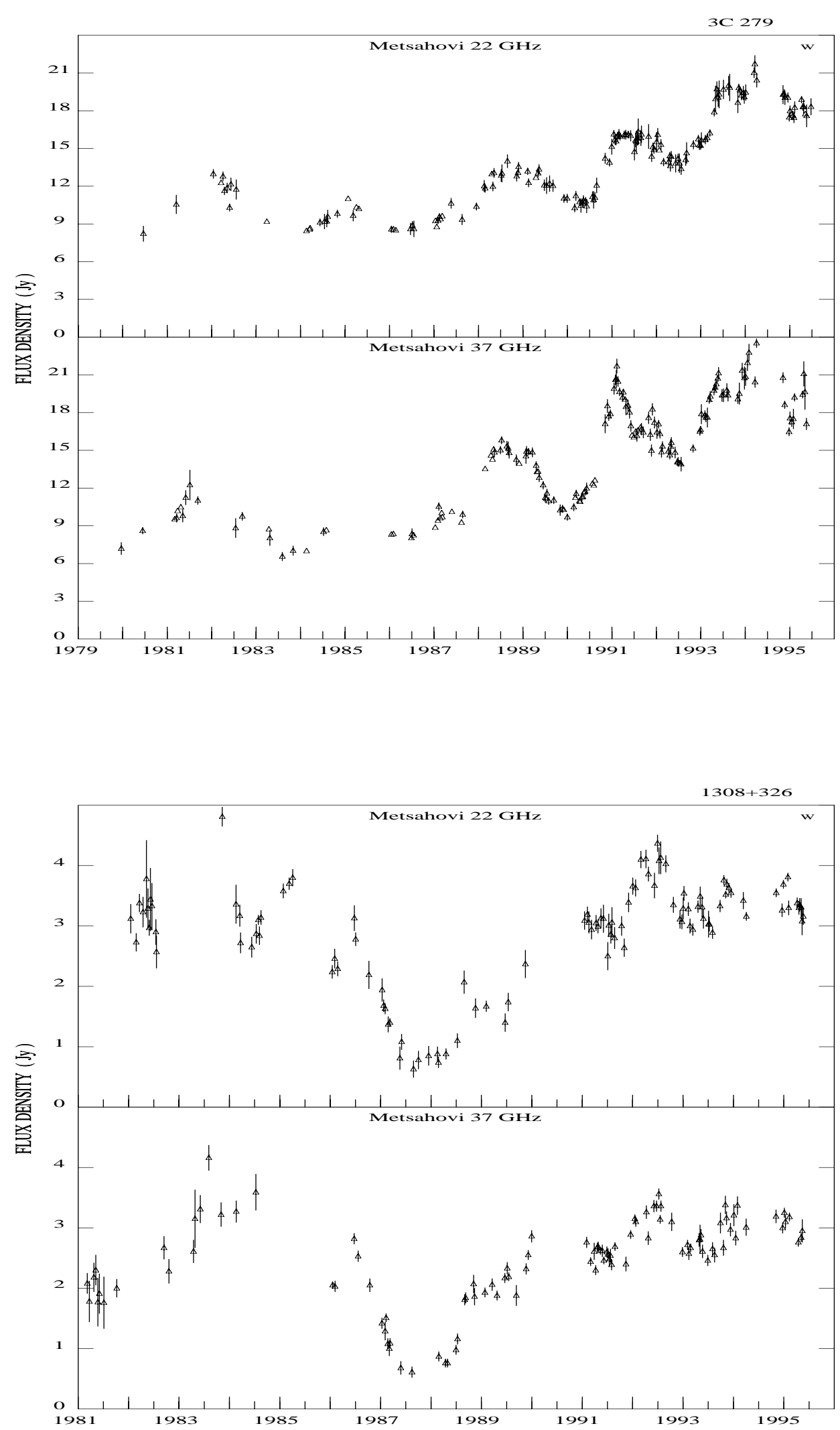

Fig. 1. continued 

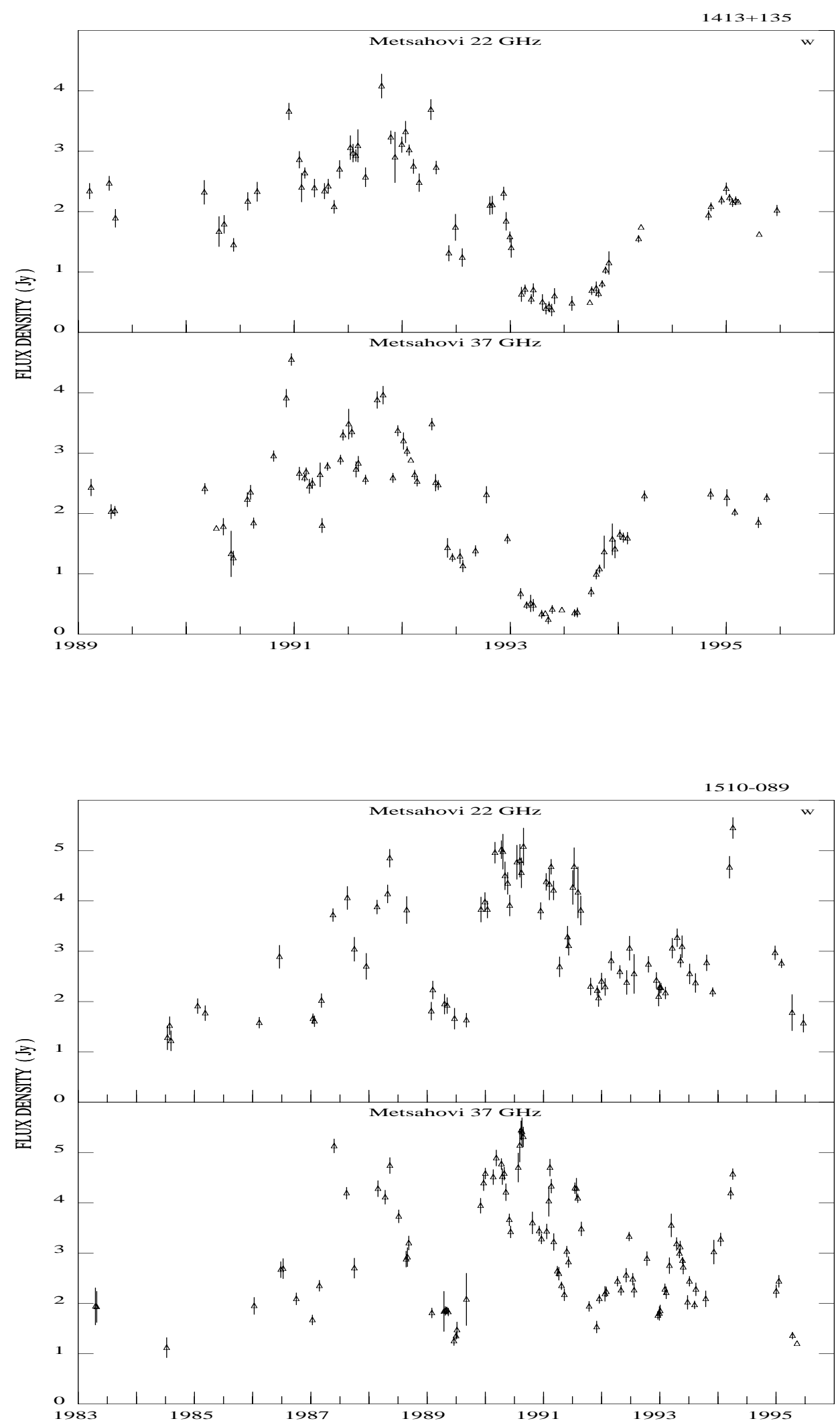

Fig. 1. continued 
324

H. Teräsranta et al.: Fifteen years monitoring of extragalactic radio sources at 22,37 and $87 \mathrm{GHz}$
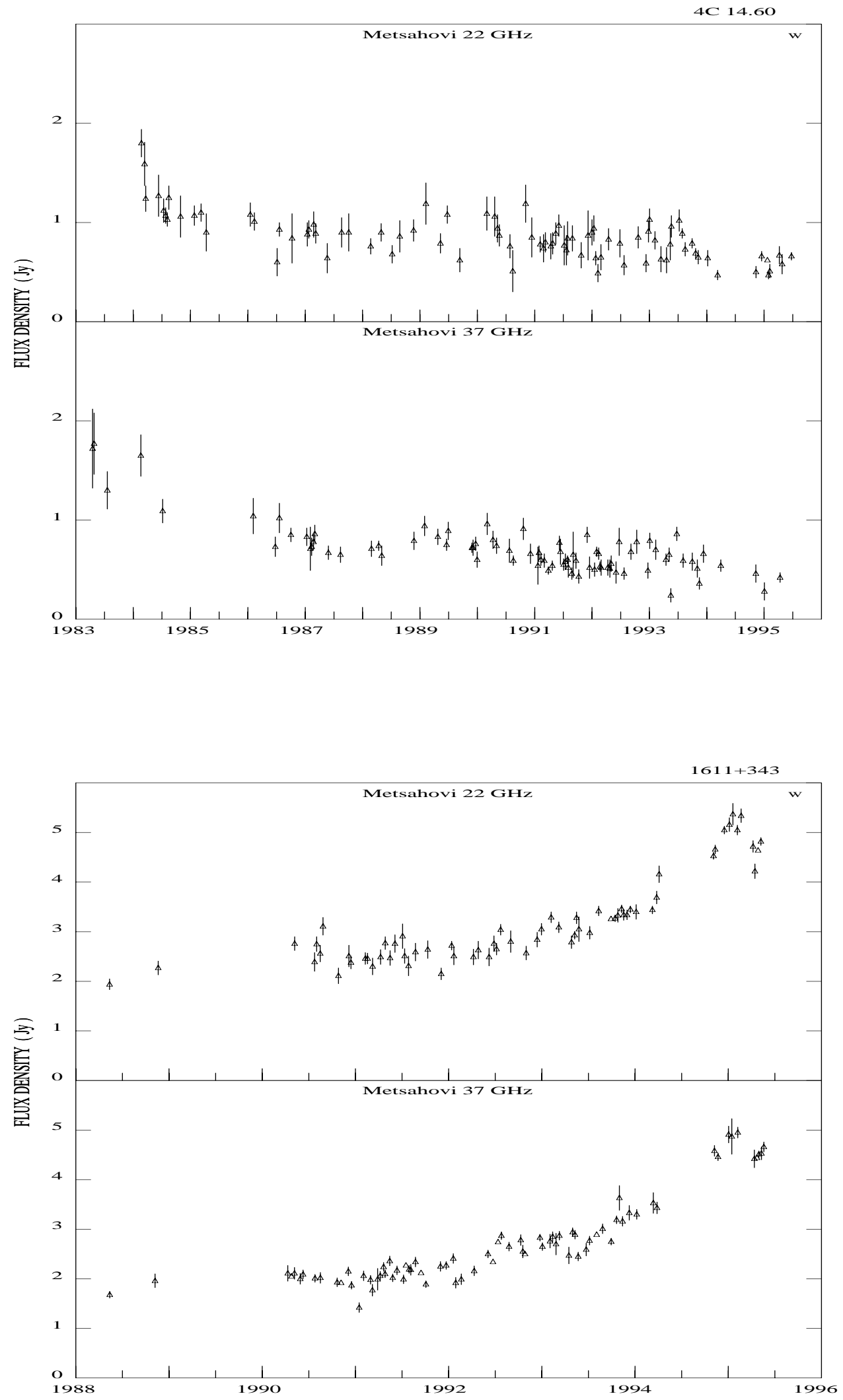

Fig. 1. continued 

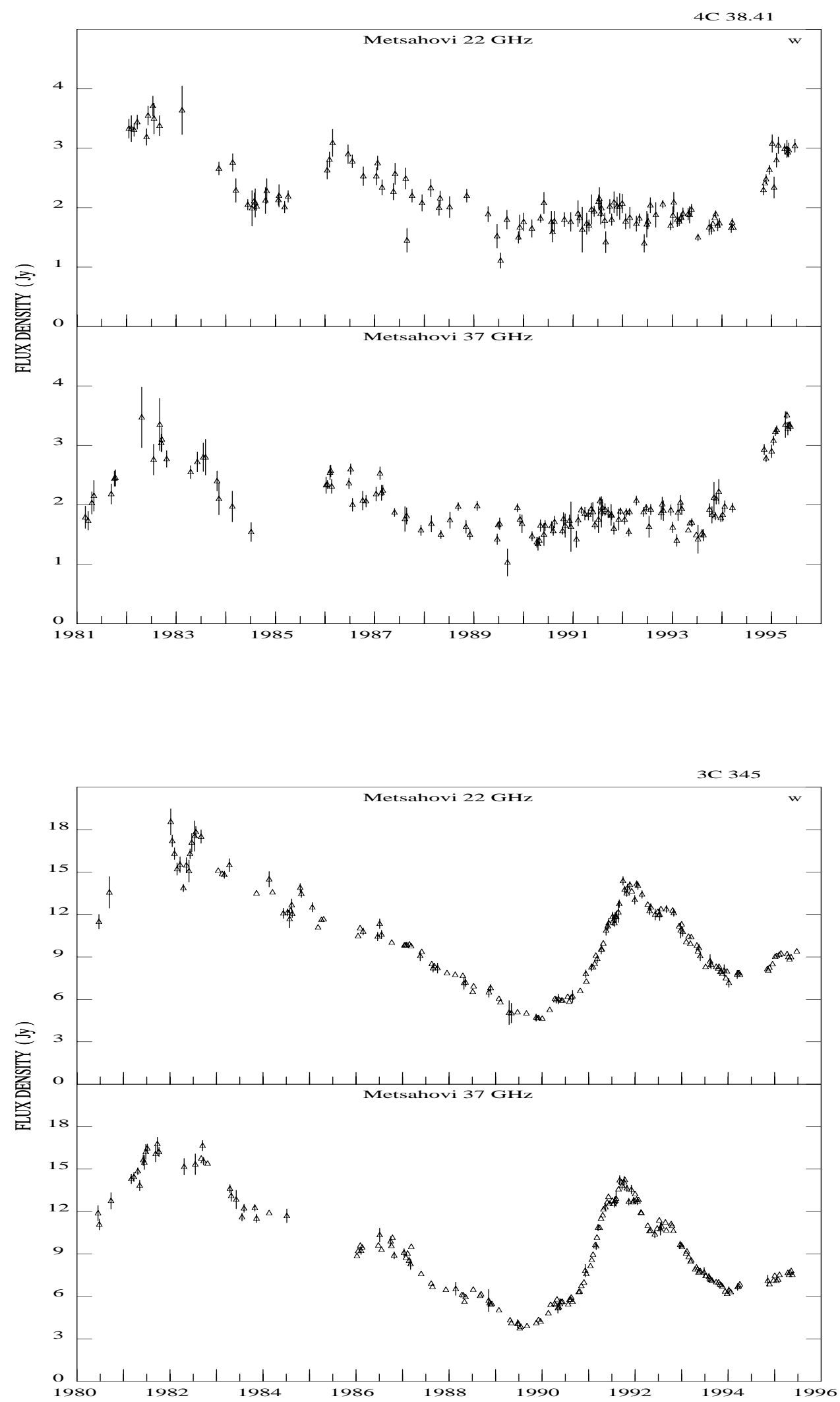

Fig. 1. continued 

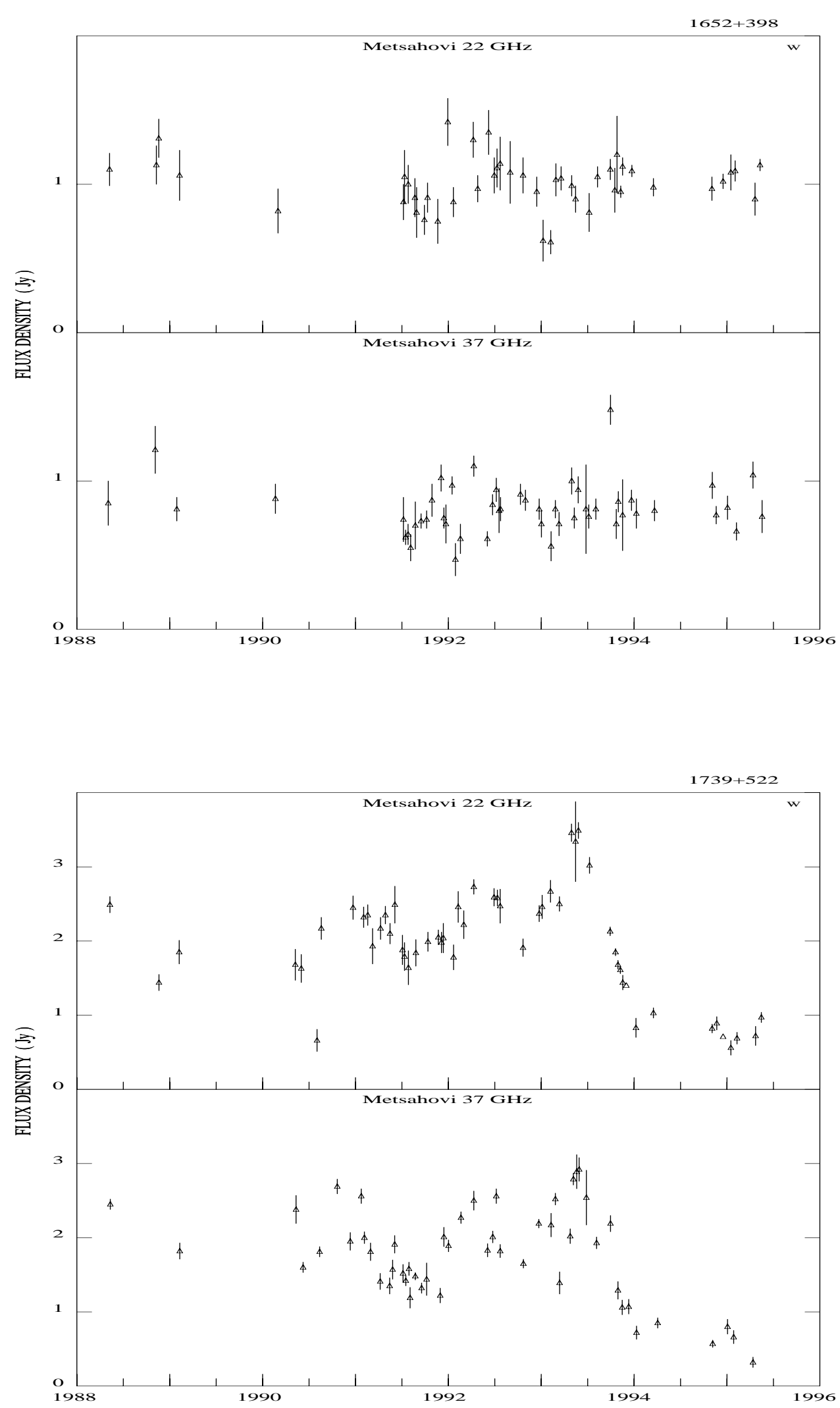

Fig. 1. continued 

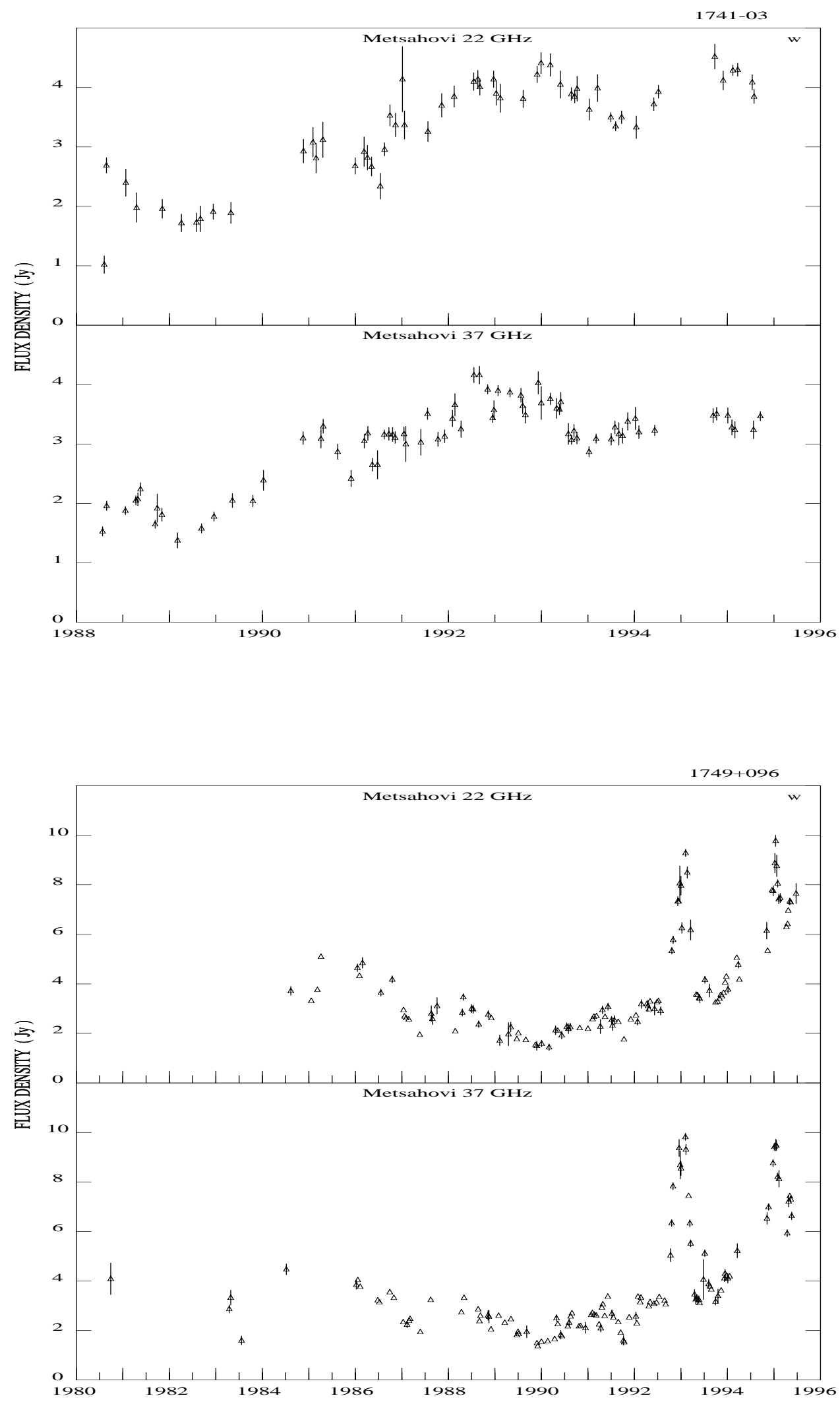

Fig. 1. continued 

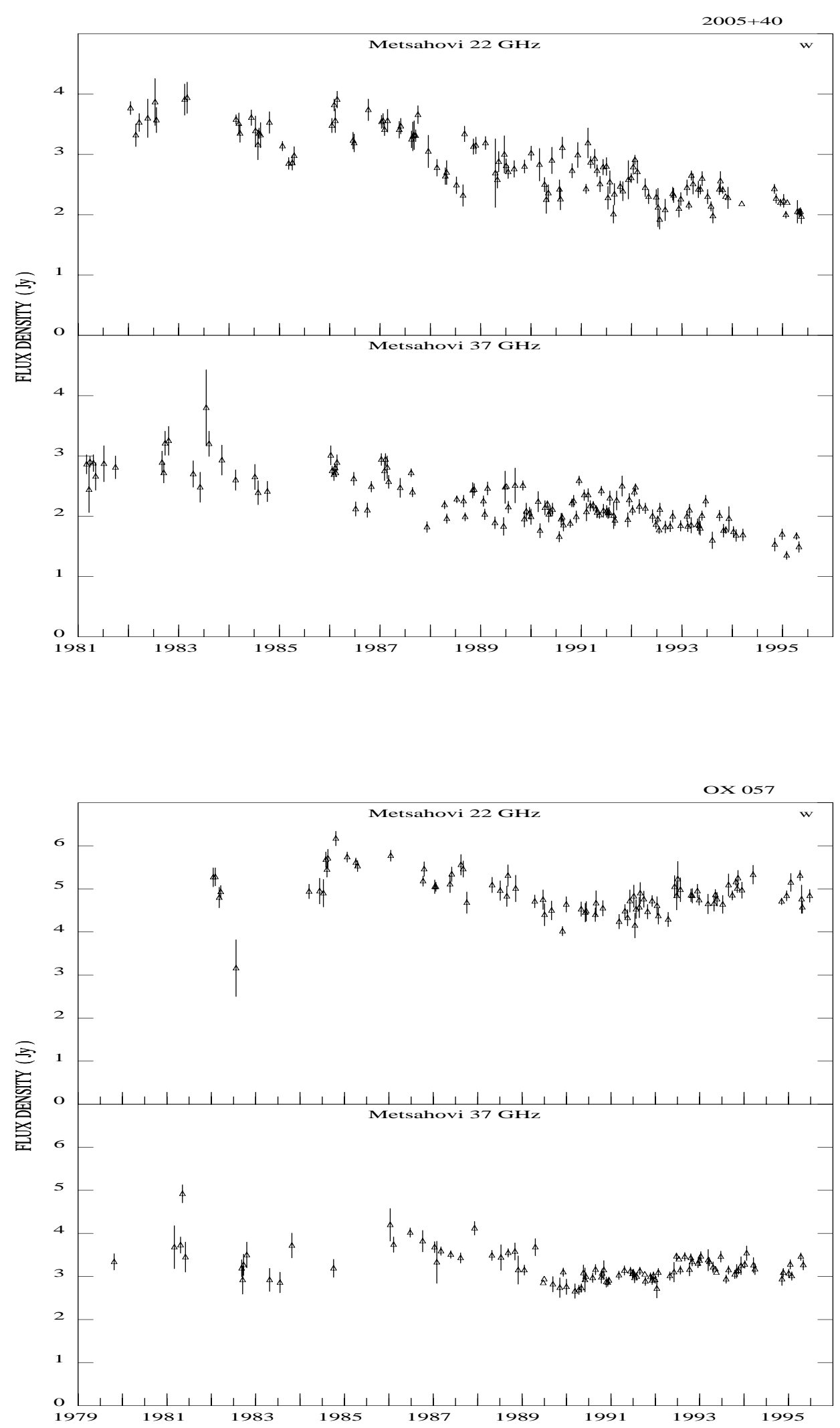

Fig. 1. continued 

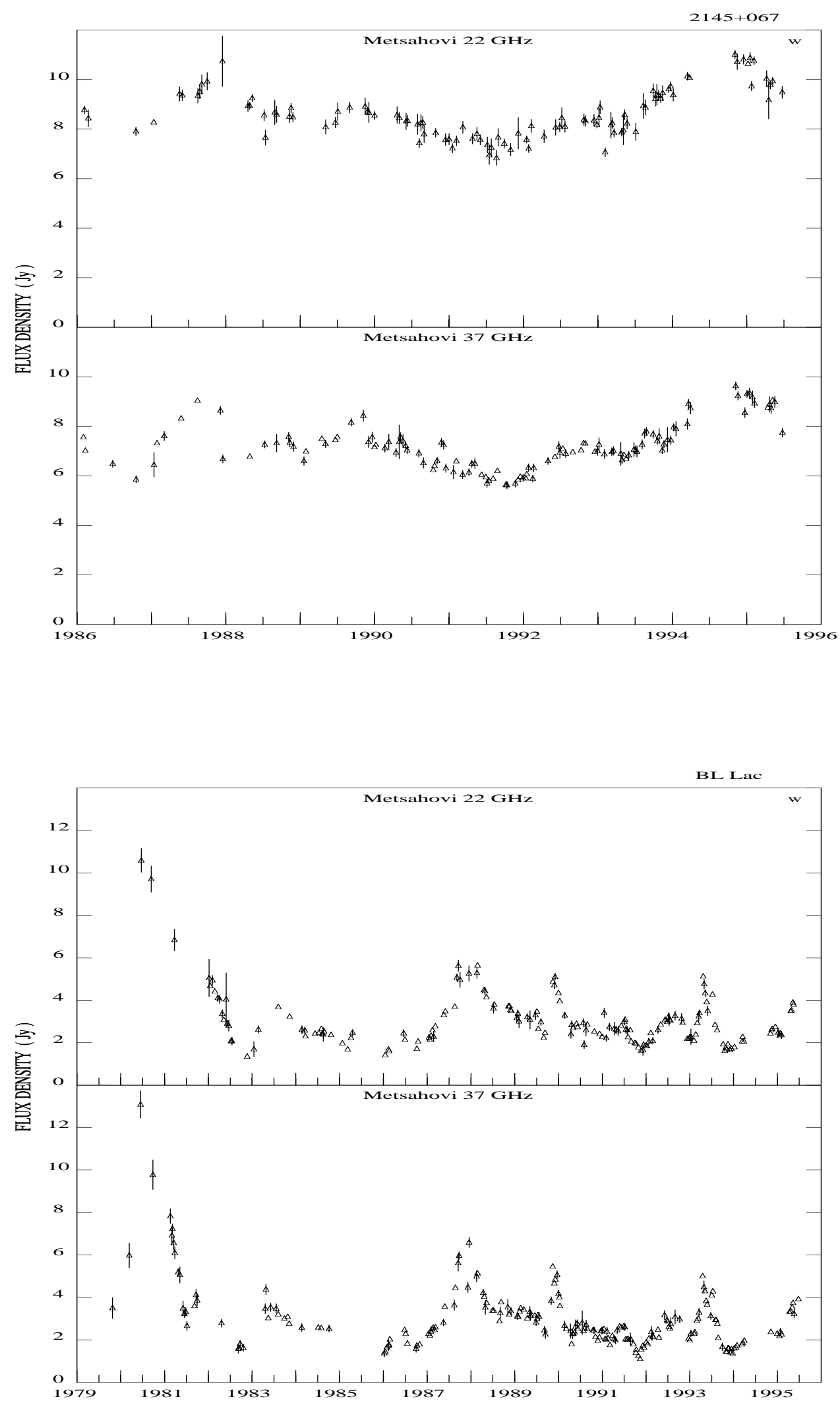

Fig. 1. continued 

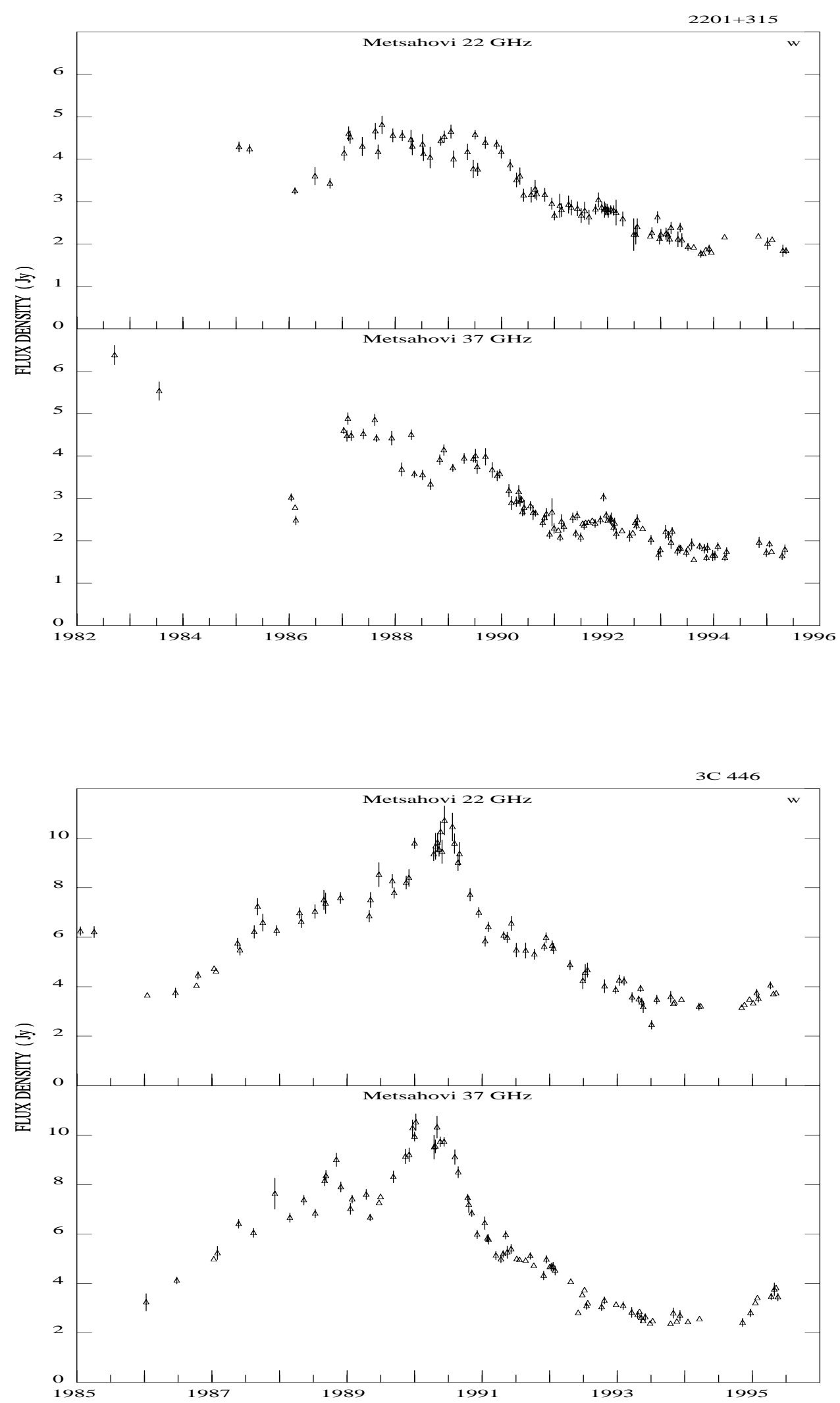

Fig. 1. continued 

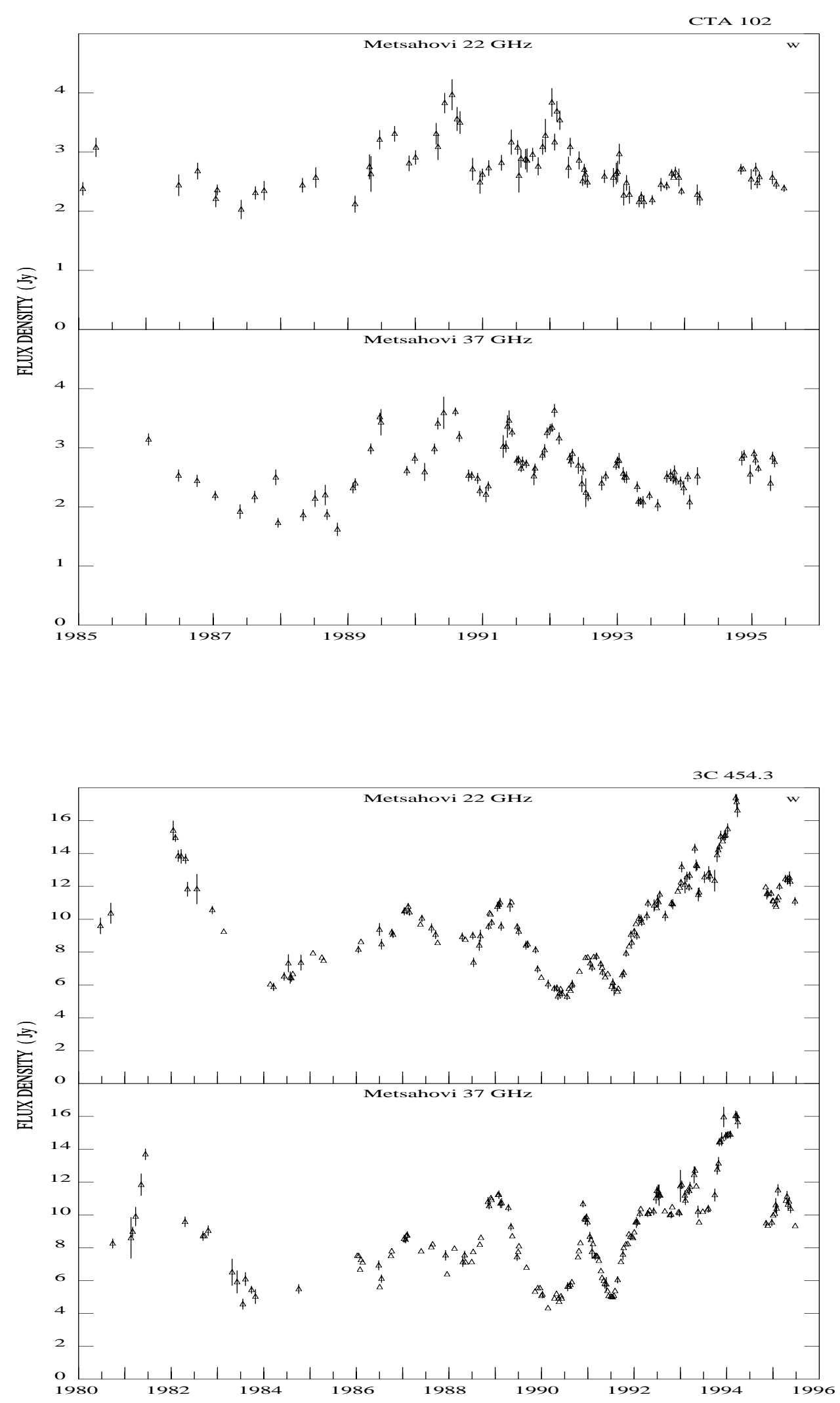

Fig. 1. continued 